IZA DP No. 9364

Countercyclical Recruiting Rates and the Value of Jobs

Eran Yashiv

September 2015 


\title{
Countercyclical Recruiting Rates and the Value of Jobs
}

\author{
Eran Yashiv \\ Tel Aviv University \\ and IZA
}

\section{Discussion Paper No. 9364 \\ September 2015}

\author{
IZA \\ P.O. Box 7240 \\ 53072 Bonn \\ Germany \\ Phone: +49-228-3894-0 \\ Fax: +49-228-3894-180 \\ E-mail: iza@iza.org
}

Any opinions expressed here are those of the author(s) and not those of IZA. Research published in this series may include views on policy, but the institute itself takes no institutional policy positions. The IZA research network is committed to the IZA Guiding Principles of Research Integrity.

The Institute for the Study of Labor (IZA) in Bonn is a local and virtual international research center and a place of communication between science, politics and business. IZA is an independent nonprofit organization supported by Deutsche Post Foundation. The center is associated with the University of Bonn and offers a stimulating research environment through its international network, workshops and conferences, data service, project support, research visits and doctoral program. IZA engages in (i) original and internationally competitive research in all fields of labor economics, (ii) development of policy concepts, and (iii) dissemination of research results and concepts to the interested public.

IZA Discussion Papers often represent preliminary work and are circulated to encourage discussion. Citation of such a paper should account for its provisional character. A revised version may be available directly from the author. 
IZA Discussion Paper No. 9364

September 2015

\section{ABSTRACT}

\section{Countercyclical Recruiting Rates and the Value of Jobs}

U.S. CPS gross flows data indicate that in recessions firms actually increase their hiring rates from the pools of the unemployed and out of the labor force. Why so? The paper provides an explanation by studying the optimal recruiting behavior of the representative firm. This behavior is a function of the value of jobs, i.e., the expected present value of the marginal worker to the firm. Job values are estimated to be counter-cyclical in U.S. data, the underlying reason being the dynamic behavior of the labor share of GDP. The countercyclicality of hiring rates and job values, which may appear counter-intuitive, is shown to be consistent with well-known business cycle facts, such as pro-cyclical employment and procyclical vacancy and job-finding rates (as well as job to job flows). The analysis emphasizes the difference between current labor productivity and the forward-looking concept of job value. The paper explains the high volatility of firm recruiting behavior, as well as the reduction in labor market fluidity in the U.S. over time, using the same framework.

JEL Classification: E24, E32

Keywords: firm recruitment, job values, business cycles, vacancies, hiring, labor market frictions, volatility, labor market fluidity

Corresponding author:

Eran Yashiv

The Eitan Berglas School of Economics

Tel Aviv University

Tel Aviv 69978

Israel

E-mail: yashiv@post.tau.ac.il 


\section{Countercyclical Recruiting Rates and the Value of Jobs ${ }^{1}$}

\section{Introduction}

The paper asks what governs the representative firm recruiting behavior along the business cycle. This behavior is important for our understanding of business cycles and employment dynamics. In particular, I look at the optimality equation of the firm, which equates the marginal cost of worker recruitment and the expected present value of the worker for the firm, i.e., the job value. I examine the issue empirically by estimating alternative specifications of the equation. Estimation rests on key formulations in the literature, particularly the ones related to search and matching models. Following estimation, I analyze the cyclical behavior of job values and examine their components.

The main findings are as follows:

(i) Job values are counter-cyclical in U.S. data. This means that in recessions the value of jobs for firms goes up. Note that this value is a forwardlooking expected present value of future labor profitability.

(ii) Correspondingly, hiring rates from non-employment (unemployment + out of the labor force) are counter-cyclical: it is worthwhile for firms to increase hiring rates as job values rise in recessions.

(iii) While the afore-mentioned hiring rates are counter-cyclical, vacancy rates and hiring rates from employment (i.e., job to job flows) are procyclical. The differences between points (ii) and (iii) are explained.

(iv) While point (i), the counter-cyclicality of job values, may appear counter-intuitive, it is consistent with the findings of recent studies looking at the cyclical behavior of the labor share in GDP. It is the dynamic behavior of the labor share that engenders the counter-cyclicality of the forwardlooking job values.

(v) Points (i) and (ii) do not contradict what we already know about the cyclical features of the labor market, including pro-cyclical employment and job finding rates.

(vi) Moving from cyclicality to volatility, the high volatility of vacancy and hiring rates is explained within the same framework. Part of the explanation has to do with job values and another part with the interaction of recruitment behavior with capital investment behavior, an issue which has typically been overlooked.

(vii) The secular phenomenon of a reduction in labor market fluidity

\footnotetext{
${ }^{1}$ I am grateful to Larry Christiano and Giuseppe Moscarini for very useful discussions; to seminar partcipants at the Dale Mortensen memorial conference (Aarhus, October 2014) and at the CEPR ESSIM conference (Tarragona, May 2015) for useful comments; and to Avihai Lifschitz, Andrey Perlin and Ziv Usha for excellent research assistance. Any errors are my own.
} 
in the U.S. over time, noted by Davis and Haltiwanger (2014), is also accounted for using the same framework.

The paper proceeds as follows: Section 2 presents the context of the paper in the literature. Section 3 presents the model and the key relations to be empirically examined. The data and methodology are elaborated in Section 4, followed by the presentation of the cyclical behavior of the key data series in Section 5. The results of the empirical work are presented in Section 6 and their cyclical implications are elaborated in Section 7. Section 8 studies the volatility of the series related to recruitment (vacancy and hiring rates) and relates them to the estimated job values. Section 9 elaborates on the connections of the results to the dynamics of the labor share in GDP, recently discussed in other Macro contexts. In Section 10 I use this framework to explain the decline in U.S. labor market fluidity. Section 11 concludes. Derivations and other technical matters are relegated to appendices.

\section{The Paper in the Context of the Literature}

This paper focuses on the firms' optimal recruiting behavior in the presence of frictions. To see how recent literature has approached this topic, it may be useful to discuss this behavior using the following simple equation:

$$
M C_{t}(\cdot)=E_{t} P V_{t}(\cdot)
$$

The equation relates the marginal costs of vacancies or of hiring which the firm faces with the marginal benefit, which is the expected present value of what the firm will get from the employment relationship. Table 1 lists 13 key studies and reports what these studies have posited with respect to the LHS and the RHS of equation (1). Appendix A presents the full equation as formulated by each study. The studies are divided into two groups - those positing linear costs and those positing convex costs.

\section{Table 1}

Beyond the differences between linear and convex costs, the table shows that the different permutations of formulating the equation include:

(i) Single job vs large firms.

(ii) Using vacancies or actual hires as arguments of the cost function.

(iii) Formulating labor only or capital and labor as determining productivity.

(iv) Wages (appearing on the RHS) being determined by the Nash solution, intrafirm bargaining, credible bargaining or sticky wage mechanisms.

(v) Worker separations modeled as exogenous or endogenous, constant or stochastic. 
(vi) Discounting the future with a constant or time-varying rate; for the latter, there are different formulations (IMRS, WACC or derived from the stock market).

The current paper looks at a number of alternative specifications. The key one has large firms and convex costs; takes into account both vacancies and actual hires as arguments of the cost function; includes capital as well as labor; models capital adjustment frictions as well as labor frictions; uses actual wages and separation rates, without explicitly modelling how they are determined; and uses a time-varying IMRS-type discount rate.

In previous work - Merz and Yashiv (2007) and Yashiv (2015) - I have also used this formulation, or special cases of it. The former paper did so in the context of studying the determinants of the market value of U.S. firms. The idea there is that the value of investment and the value of hiring make up the value of the firm. The latter paper uses the formulation above to analyze the joint, forward-looking behavior of hiring and investment, examining their inter-relationships and the determinants of their present values. In contrast, the current paper focuses on job values and their implications for recruiting behavior over the business cycle. In particular, it relates those to the behavior of the labor share over the cycle. It does so using an updated data set, covering the Great Recession and its aftermath, examining alternative specifications, and undertaking decompositions of the determinants of job values and recruitment rates.

\section{The Model}

I present a model of firm optimization, which includes capital as well as labor, and formulate the costs function underlying the problem in such a way that the cases shown in Table 1 above will mostly be special cases.

\subsection{The General Model}

Set-Up. There are identical workers and identical firms, who live forever and have rational expectations.

Worker Flows. Consider worker flows. The flow from non-employment - unemployment $(U)$ and out of the labor force $(O)$ - to employment is to be denoted $O E+U E$ and the separation flow in the opposite direction, $E U+E O$. Worker flows within employment - i.e., job to job flows - are to be denoted $E E$.

I shall denote: 


$$
\begin{aligned}
\frac{h}{n} & =\left(\frac{h^{1}}{n}\right)+\left(\frac{h^{2}}{n}\right) \\
\frac{h^{1}}{n} & =\frac{O E+U E}{E} \\
\frac{h^{2}}{n} & =\frac{E E}{E}
\end{aligned}
$$

Hence $h^{1}$ and $h^{2}$ denote flows from non-employment and from other employment, respectively.

Separation rates are given in an analogous way by:

$$
\begin{aligned}
\psi & =\psi^{1}+\psi^{2} \\
\psi^{1} & =\frac{E O+E U}{E} \\
\psi^{2} & =\frac{E E}{E}=\frac{h^{2}}{n}
\end{aligned}
$$

Employment dynamics are thus given by:

$$
\begin{aligned}
n_{t+1} & =\left(1-\psi_{t}^{1}-\psi_{t}^{2}\right) n_{t}+h_{t}^{1}+h_{t}^{2} \\
& =\left(1-\psi_{t}\right) n_{t}+h_{t}, \quad 0 \leq \psi_{t} \leq 1 \\
h_{t}^{2} & =\psi_{t}^{2} n_{t}
\end{aligned}
$$

Matching and Separations. ${ }^{2}$ Firms hire from non-employment $\left(h_{t}^{1}\right)$ and from other firms $\left(h_{t}^{2}\right)$. Each period, the worker's effective units of labor (normally 1 per person) depreciate to 0 , in the current firm, with some exogenous probability $\psi_{t}$. Thus, the match suffers an irreversible idiosyncratic shock that makes it no longer viable. The worker may be reallocated to a new firm where his/her productivity is (temporarily) restored to 1 . This happens with a probability of $\psi_{t}^{2}$. Those who are not reallocated join unemployment, with probability $\psi_{t}^{1}=\psi_{t}-\psi_{t}^{2}$. So the fraction $\psi_{t}^{2}$ that enters job to job flows depends on the endogenous hiring flow $h_{t}^{2}$. The firm decides how many vacancies $v_{t}$ to open and, given job filling rates $\left(q_{t}^{1}, q_{t}^{2}\right)$, will get to hire from the pre-existing non-employed and from the pool of matches just gone sour. The job-filling or matching rates satisfy:

$$
\begin{aligned}
& q_{t}^{1}=\frac{h_{t}^{1}}{v_{t}} \\
& q_{t}^{2}=\frac{h_{t}^{2}}{v_{t}} \\
& q_{t}=q_{t}^{1}+q_{t}^{2}
\end{aligned}
$$

\footnotetext{
${ }^{2}$ I am indebted to Giuseppe Moscarini for very useful suggestions to this section.
} 
Firms Optimization. Firms make gross investment $\left(i_{t}\right)$ and vacancy $\left(v_{t}\right)$ decisions. Once a new worker is hired, the firm pays him or her a perperiod wage $w_{t}$. Firms use physical capital $\left(k_{t}\right)$ and labor $\left(n_{t}\right)$ as inputs in order to produce output goods $y_{t}$ according to a constant-returns-to-scale production function $f$ with productivity shock $z_{t}$ :

$$
y_{t}=f\left(z_{t}, n_{t}, k_{t}\right),
$$

Gross hiring and gross investment are subject to frictions, spelled out below, and hence are costly activities. I represent these costs by a function $g\left[i_{t}, k_{t}, v_{t}, h_{t}, n_{t}\right]$ which is convex in the firm's decision variables and exhibits constant returns-to-scale, allowing hiring costs and investment costs to interact.

In every period $t$, the capital stock depreciates at the rate $\delta_{t}$ and is augmented by new investment $i_{t}$. Similarly, workers separate at the rate $\psi_{t}$ and the employment stock is augmented by new hires $q_{t} v_{t}=h_{t}$. The laws of motion are:

$$
\begin{gathered}
k_{t+1}=\left(1-\delta_{t}\right) k_{t}+i_{t}, \quad 0 \leq \delta_{t} \leq 1 . \\
n_{t+1}=\left(1-\psi_{t}\right) n_{t}+q_{t} v_{t}, \quad 0 \leq \psi_{t} \leq 1
\end{gathered}
$$

The representative firm chooses sequences of $i_{t}$ and $v_{t}$ in order to maximize its profits as follows:

$\max _{\left\{i_{t+j}, v_{t+j}\right\}} E_{t} \sum_{j=0}^{\infty}\left(\prod_{i=0}^{j} \rho_{t+i}\right)\left(1-\tau_{t+j}\right)\left(\begin{array}{c}f\left(z_{t+j}, n_{t+j}, k_{t+j}\right)-g\left(i_{t+j}, k_{t+j}, v_{t+j}, h_{t+j}, n_{t+j}\right) \\ -w_{t+j} n_{t+j}-\left(1-\chi_{t+j}-\tau_{t+j} D_{t+j}\right) \widetilde{p}_{t+j}^{I} i_{t+j}\end{array}\right)$

subject to the constraints (7) and (8), where $\tau_{t}$ is the corporate income tax rate, $w_{t}$ is the wage, $\chi_{t}$ the investment tax credit, $D_{t}$ the present discounted value of capital depreciation allowances, $\tilde{p}_{t}^{I}$ the real pre-tax price of investment goods, and $\rho_{t+j}$ is a time-varying discount factor. The firm takes the paths of the variables $q_{t}, w_{t}, \psi_{t}, p_{t}^{I}, \delta_{t}, \tau_{t}$ and $\rho_{t}$ as given. This is consistent with the standard models in the search and matching and Tobin's q literatures. The Lagrange multipliers associated with these two constraints are denoted $Q_{t+j}^{K}$ and $Q_{t+j}^{N}$, respectively. These Lagrange multipliers can be interpreted as marginal $Q$ for physical capital, and marginal $Q$ for employment, respectively. I shall use the term capital value or present value of investment for the former and job value or present value of hiring for the latter. 
The first-order conditions for dynamic optimality are: ${ }^{3}$

$$
\begin{gathered}
Q_{t}^{K}=E_{t}\left[\rho_{t+1}\left[\left(1-\tau_{t+1}\right)\left(f_{k_{t+1}}-g_{k_{t+1}}\right)+\left(1-\delta_{t+1}\right) Q_{t+1}^{K}\right]\right] \\
Q_{t}^{K}=\left(1-\tau_{t}\right)\left(g_{i_{t}}+p_{t}^{I}\right) \\
Q_{t}^{N}=E_{t}\left[\rho_{t+1}\left[\left(1-\tau_{t+1}\right)\left(f_{n_{t+1}}-g_{n_{t+1}}-w_{t+1}\right)+\left(1-\psi_{t+1}\right) Q_{t+1}^{N}\right]\right] \\
Q_{t}^{N}=\left(1-\tau_{t}\right) \frac{g_{v_{t}}}{q_{t}}
\end{gathered}
$$

Using these equations, the following expression captures the RHS of equation (1), the present value of the job to the firm:

$$
P V_{t}=\rho_{t, t+1}\left(1-\tau_{t+1}\right)\left[\begin{array}{c}
f_{n_{t+1}}-g_{n_{t+1}}-w_{t+1} \\
+\left(1-\psi_{t+1}\right) \frac{g_{v_{t+1}}}{q_{t+1}}
\end{array}\right]
$$

Basically $P V_{t}$ is the present value of the profit flows from the marginal worker $f_{n_{t+j}}-g_{n_{t+j}}-w_{t+j}$ for $j=1 \ldots \infty$ adjusted for taxes $\left(\tau_{t+j}\right)$ and separation rates $\left(\psi_{t+j}\right)$.

I can summarize the firm's first-order necessary conditions from equations (10)-(13) by the following two expressions:

$$
\begin{gathered}
\left(1-\tau_{t}\right)\left(g_{i_{t}}+p_{t}^{I}\right)=E_{t}\left[\rho_{t, t+1}\left(1-\tau_{t+1}\right)\left[\begin{array}{c}
f_{k_{t+1}}-g_{k_{t+1}} \\
+\left(1-\delta_{t+1}\right)\left(g_{i_{t+1}}+p_{t+1}^{I}\right)
\end{array}\right]\right] \\
\left(1-\tau_{t}\right) \frac{g_{v_{t}}}{q_{t}}=E_{t}\left[\rho_{t, t+1}\left(1-\tau_{t+1}\right)\left[\begin{array}{c}
f_{n_{t+1}}-g_{n_{t+1}}-w_{t+1} \\
+\left(1-\psi_{t+1}\right) \frac{g_{v_{t+1}}}{q_{t+1}}
\end{array}\right]\right]
\end{gathered}
$$

Equation (16) is at the focal point of the analysis and gives structure to equation (1) above. Following the explicit formulation of the costs function $g$ I shall consider alternative, specific cases. Equation (15) is estimated jointly with equation (16). The estimated equations are spelled out in Appendix B.

The costs function $g$, capturing the different frictions in the hiring and investment processes, is at the focus of the estimation work. Specifically, hiring costs include costs of advertising, screening and testing, matching frictions, training costs and more. Investment involves implementation costs, financial premia on certain projects, capital installation costs, learning the use of new equipment, etc. Both activities may involve, in addition

${ }^{3}$ where I use the real after-tax price of investment goods, given by:

$$
p_{t+j}^{I}=\frac{1-\chi_{t+j}-\tau_{t+j} D_{t+j}}{1-\tau_{t+j}} \widetilde{p}_{t+j}^{I} .
$$


to production disruption, the implementation of new organizational structures within the firm and new production techniques. ${ }^{4}$ In sum $g$ is meant to capture all the frictions involved in getting workers to work and capital to operate in production, and not, say, just capital adjustment costs or vacancy costs. One should keep in mind that this is formulated as the costs function of the representative firm within a macroeconomic model, and not one of a single firm in a heterogenous firms micro set-up.

Functional Form. The parametric form I use is the following, generalized convex function.

$$
g(\cdot)=\left[\begin{array}{c}
\frac{e_{1}}{\eta_{1}}\left(\frac{i_{t}}{k_{t}}\right) \eta_{1} \\
+\frac{e_{2}}{\eta_{2}}\left[\frac{\left(1-\lambda_{1}-\lambda_{2}\right) v_{t}+\lambda_{1} q_{t}^{1} v_{t}+\lambda_{2} q_{t}^{2} v_{t}}{n_{t}}\right]^{\eta_{2}} \\
+\frac{e_{31}}{\eta_{31}}\left(\frac{i_{t}}{k_{t}} \frac{q_{t}^{1} v_{t}}{n_{t}}\right)^{\eta_{31}}+\frac{e_{32}}{\eta_{32}}\left(\frac{i_{t}}{k_{t}} \frac{q_{t}^{2} v_{t}}{n_{t}}\right)^{\eta_{32}}
\end{array}\right] f\left(z_{t}, n_{t}, k_{t}\right) .
$$

This function is linearly homogenous in its arguments $i, k, v, h, n$. The parameters $e_{l}, l=1,2,31,32$ express scale, and the parameters $\eta_{1}, \eta_{2}, \eta_{31}, \eta_{32}$ express the convexity of the costs function with respect to its different arguments. $\lambda_{1}$ is the weight in the cost function assigned to hiring from nonemployment $\left(\frac{h_{t}^{1}}{n_{t}}\right), \lambda_{2}$ is the weight assigned to hiring from other firms $\left(\frac{h_{t}^{2}}{n_{t}}\right)$, and $\left(1-\lambda_{1}-\lambda_{2}\right)$ is the weight assigned to vacancy $\left(\frac{v_{t}}{n_{t}}\right)$ costs. The weights $\lambda_{1}$ and $\lambda_{2}$ are thus related to the training and production disruption aspects, while the complementary weight is related to the vacancy creation and recruiting aspects. The last two terms in square brackets capture interactions between investment and hiring. I rationalize the use of this form in what follows.

Arguments of the function. This specification captures the idea that frictions or costs increase with the extent of the activity in question - vacancy creation, hiring and investment. This needs to be modelled relative to the size of the firm. The intuition is that hiring 10 workers, for example, means different levels of hiring activity for firms with 100 workers or for firms with 10,000 workers. Hence firm size, as measured by its physical capital stock or its level of employment, is taken into account and the costs function is increasing in the vacancy, hiring and investment rates, $\frac{v}{n}, \frac{h}{n}$ and $\frac{i}{k}$. The function used postulates that costs are proportional to output, i.e., the results can be stated in terms of lost output.

More specifically, the terms in the function presented above may be justified as follows (drawing on Garibaldi and Moen (2009)): suppose each worker $i$ makes a recruiting and training effort $h_{i}$; as this is to be modelled as a convex function, it is optimal to spread out the efforts equally across workers so $h_{i}=\frac{h}{n}$; formulating the costs as a function of these efforts and putting them in terms of output per worker one gets $c\left(\frac{h}{n}\right) \frac{f}{n}$; as $n$ workers

\footnotetext{
${ }^{4}$ See Alexopoulos (2011) and Alexopoulos and Tombe (2012).
} 
do it then the aggregate cost function is given by $c\left(\frac{h}{h}\right) f$.

Convexity. I use a convex function. While non-convexities were found to be significant at the micro level (plant, establishment, or firm), a number of recent papers have given empirical support for the use of a convex function in the aggregate, showing that such a formulation is appropriate at the macroeconomic level. ${ }^{5}$

Interaction. The terms $\frac{e_{31}}{\eta_{31}}\left(\frac{i_{t}}{k_{t}} \frac{q_{t}^{1} v_{t}}{n_{t}}\right)^{\eta_{31}}$ and $\frac{e_{32}}{\eta_{32}}\left(\frac{i_{t}}{k_{t}} \frac{q_{t}^{2} v_{t}}{n_{t}}\right)^{\eta_{32}}$ express the interaction of investment and hiring costs. They allow for a different interaction for hires from non-employment $\left(h_{t}^{1}\right)$ and from other firms $\left(h_{t}^{2}\right)$. These terms, absent in many studies, have important implications for the complementarity of investment and hiring.

\subsection{Alternative Specifications}

Beyond the general model spelled out above, which nests most of the specifications of Table 1, I specifically examine two special cases.

\subsubsection{Tobin's q Approach}

As shown in the second group of studies in Table 1 above, there is a formulation of optimal hiring with convex costs following the logic of the literature on investment models, mostly the seminal contributions of Lucas and Prescott (1971) and of Tobin (1969) and Hayashi (1982). This approach ignores the other factor of production (i.e., assumes no adjustment costs for it). In the current case, investment in capital is assumed to have no adjustment costs. Typically quadratic costs are posited (for vacancies and hiring). Hence in this case $e_{1}=e_{31}=e_{32}=0$ and $\eta_{2}=2$. The optimality equation becomes:

$$
\left(1-\tau_{t}\right) \frac{e_{2}}{q_{t}}\left[\left(1-\lambda_{1}-\lambda_{2}\right)+\lambda_{1} q_{t}^{1}+\lambda_{2} q_{t}^{2}\right]^{2} \frac{v_{t}}{n_{t}}=E_{t} \frac{1}{\frac{f_{t}}{n_{t}}}\left[\rho_{t, t+1}\left(1-\tau_{t+1}\right)\left[\begin{array}{c}
f_{n_{t+1}}-g_{n_{t+1}}-w_{t+1} \\
+\left(1-\psi_{t+1}\right) \frac{g_{v}}{q_{t+1}}
\end{array}\right]\right]
$$

\subsubsection{The Standard Search and Matching Model}

The standard search and matching model does not consider investment when formulating costs and refers to linear vacancy costs. It refers to vacancies only (not to hiring). In terms of the model above it has $e_{1}=e_{31}=$

\footnotetext{
${ }^{5}$ Thus, Thomas (2002) and Kahn and Thomas (2008, see in particular their discussion on pages 417-421) study a dynamic, stochastic, general equilibrium model with nonconvex capital adjustment costs. One key idea which emerges from their analysis is that there are smoothing effects that result from equilibrium price changes.
} 
$e_{32}=0, \lambda_{1}=\lambda_{2}=0$ and $\eta_{2}=1$. It thus formulates the optimality equation for vacancy creation $\left(v_{t}\right)$ as follows, i.e., this is equation (16) for this particular model.

$$
\left(1-\tau_{t}\right) \frac{e_{2}}{q_{t}} \frac{f_{t}}{n_{t}}=E_{t}\left[\rho_{t+1}\left(1-\tau_{t+1}\right)\left[f_{n_{t+1}}-w_{t+1}+\left(1-\psi_{t+1}\right) \frac{e_{2}}{q_{t+1}} \frac{f_{t+1}}{n_{t+1}}\right]\right]
$$

As shown in the first group of studies in Table 1 above, and further discussed in Appendix A, this is a prevalent formulation, that has total costs be a linear function of vacancies, i.e., $\frac{e_{2}}{q_{t}} \frac{f_{t}}{n_{t}} v_{t}$ whereby the cost is proportional to labor productivity $\frac{f_{t}}{n_{t}}$ and depends on the average duration of the vacancy $\frac{1}{q_{t}}\left(q_{t}\right.$ is the job filling rate, $\left.q_{t}=\frac{h_{t}}{v_{t}}\right)$.

\section{Methodology and Data}

To be empirically evaluated, the afore-going optimality equations will be estimated. I discuss the data, the estimation methodology and a postestimation approximation and variance decomposition.

\subsection{Data}

The data are quarterly and pertain to the private sector of the U.S. economy. For a large part of the empirical work reported below the sample period is 1994-2013. The start date of 1994 is due to the lack of availability of job to job worker flows $\left(h_{t}^{2}\right)$ data prior to that. For another part of the empirical work, the sample covers 1976-2013 and the 1976 start is due to the availability of credible monthly CPS data from which the gross hiring flows $\left(h_{t}^{1}\right)$ series is derived. This longer sample period covers five NBER-dated recessions, and both sample periods include the Great Recession (2007-2009) and its aftermath (2009-2013). The data include NIPA data on the Non Financial Corporate Business Sector (NFCB) GDP and its deflator, capital, investment, the price of investment goods and depreciation, BLS CPS data on employment and on worker flows, and Fed data computations on tax and depreciation allowances. Appendix $\mathrm{C}$ elaborates on the sources and on data construction. These data have the following distinctive features: (i) they pertain to the U.S. private sector; (ii) both hiring $h_{t}$ and investment $i_{t}$ refer to gross flows; likewise, separation of workers $\psi_{t}$ and depreciation of capital $\delta_{t}$ are gross flows; (iii) the estimating equations take into account taxes and depreciation allowances. Table 2 presents key sample statistics.

Table 2 


\subsection{Estimation}

I use the different model specifications discussed above. For the production function I use a standard Cobb-Douglas formulation, with productivity shock $z_{t}$ :

$$
f\left(z_{t}, n_{t}, k_{t}\right)=e^{z_{t}} n_{t}{ }^{\alpha} k_{t}^{1-\alpha}, 0<\alpha<1 .
$$

The costs function $g$ was spelled out above (see equation (17)). Estimation pertains to the parameters $\alpha ; e_{1}, e_{2}, e_{31}, e_{32} ; \eta_{1}, \eta_{2}, \eta_{31}, \eta_{32}, \lambda_{1}, \lambda_{2}$, or to a subset of these parameters.

Estimation of the parameters in the production and costs functions allows for the quantification of the derivatives $g_{i_{t}}$ and $g_{v_{t}}$ that appear in the firms' optimality equations. I structurally estimate the firms' first-order conditions - equation (16) and the associated equation (15) - using Hansen's (1982) generalized method of moments (GMM). The moment conditions estimated are those obtained under rational expectations. I formulate the equations in stationary terms by dividing the investment equation by $\frac{f_{t}}{k_{t}}$ and the vacancy/hiring equation by $\frac{f_{t}}{n_{t}}$. Appendix B spells out the first derivatives included in these equations and the estimated equations. Importantly, I check whether the estimated $g$ function fulfills the convexity requirement.

\subsection{Post Estimation Approximation and Variance Decomposition}

Post estimation I compute an approximated present value, $Q_{t}^{N}$ and its variance decomposition. Iterating forward the RHS of (16) one gets:

$$
P V_{t}=\sum_{j=1}^{\infty}\left[\begin{array}{c}
\left(\prod_{l=1}^{j} \rho_{t+l-1, t+l} \frac{\frac{f_{t+l}}{\frac{1}{t+l}_{t+l-1}}}{\frac{f_{t+l}}{n_{t+l}-1}}\right)\left(\prod_{l=2}^{j}\left(1-\psi_{t+l-1}\right)\right)\left(1-\tau_{t+j}\right) \\
\left.\alpha-\frac{g_{n_{t+j}}}{\frac{f_{t+j}}{n_{t+j}}}-\frac{w_{t+j}}{\frac{f_{t+j}}{n_{t+j}}}\right]
\end{array}\right]
$$

Following Cochrane (1992), I use the following first-order Taylor expansion to get (see Appendices D and E for details ${ }^{6}$ ):

$$
P V_{t} \cong E_{t}\left[\sum_{j=1}^{\infty} \exp \left[\sum_{l=1}^{j} g_{t+l}^{r}\right] \exp \left[\sum_{l=1}^{j} g_{t+l}^{f}\right] \exp \left[\sum_{m=l}^{j} g_{t+m-1}^{s}\right] M P_{t+j}\right]
$$

where

$$
\left.M P_{t+j} \equiv\left(1-\tau_{t+j}\right)\left(\alpha-\frac{g_{n_{t+j}}}{\frac{f_{t+j}}{n_{t+j}}}-\frac{w_{t+j}}{\frac{f_{t+j}}{n_{t+j}}}\right)\right)
$$

${ }^{6}$ Note, though, that Cochrane (1992) does a second-order rather than a first-order Taylor expansion. 


$$
\begin{aligned}
g_{t}^{f} & =\ln \left(\frac{\frac{f_{t+1}}{n_{t+1}}}{\frac{f_{t}}{n_{t}}}\right) \\
g_{t}^{s} & \equiv \ln \left(1-\psi_{t}\right) \\
g_{t}^{r} & \equiv \ln \rho_{t, t+1} \equiv \ln \left(\frac{1}{1+r_{t}}\right)
\end{aligned}
$$

tion:

Using a sample period truncated at $T$, yields the variance decomposi-

$$
\begin{aligned}
\operatorname{var}\left(P V_{t}\right) \cong & \frac{\Omega^{r} \Omega^{f} E(M P)}{1-\Omega} \sum_{j=1}^{T}(\Omega)^{j-1} \operatorname{cov}\left(P V_{t}, g_{t+j}^{r}\right)+ \\
& \frac{\Omega^{r} \Omega^{f} E(M P)}{1-\Omega} \sum_{j=1}^{T}(\Omega)^{j-1} \operatorname{cov}\left(P V_{t}, g_{t+j}^{f}\right)+ \\
& \frac{\Omega^{r} \Omega^{f} E(M P)}{1-\Omega} \sum_{j=2}^{T}(\Omega)^{j-1} \operatorname{cov}\left(P V_{t}, g_{t+j}^{s}\right)+ \\
& \Omega^{r} \Omega^{f} \sum_{j=1}^{T}(\Omega)^{j-1} \operatorname{cov}\left(P V_{t}, M P_{t+j}\right)
\end{aligned}
$$

where:

$$
\begin{aligned}
\Omega^{f} & =e^{E\left(g_{t}^{f}\right)} \\
\Omega^{s} & =e^{E\left(g_{t}^{s}\right)} \\
\Omega^{r} & =e^{E\left(g_{t}^{r}\right)} \\
\Omega & =e^{E(w)}=\Omega^{f} \Omega^{s} \Omega^{r} \\
w_{t} & \equiv\left(g_{t}^{f}+g_{t}^{s}+g_{t}^{r}\right)
\end{aligned}
$$

The variance of job values breaks down into terms relating to future discount rates $\left(g_{t+j}^{r}\right)$, productivity growth $\left(g_{t+j}^{f}\right)$, separation rates $\left(g_{t+j}^{s}\right)$ and marginal profits $\left(M P_{t+j}\right)$. In what follows I look at the relative size of the different terms on the RHS of equation (24) in order to gauge their relative importance.

\section{The Cyclical Behavior of Vacancy and Hiring Rates}

Before turning to the results of estimation, it is worthwhile to briefly examine the cyclical behavior of each of the data series themselves: hiring rates 
$\left(\frac{h_{t}^{1}}{h_{t}}\right)$ from non-employment (unemployment + OLF); hiring rates $\left(\frac{h_{t}^{2}}{n_{t}}\right)$ from employment (i.e., job to job flows); and vacancy rates $\left(\frac{v_{t}}{n_{t}}\right)$. I consider each in turn.

\subsection{Hiring from Non-Employment}

I compute $\rho\left(\frac{h_{t}^{1}}{n_{t}}, f_{t+i}\right)$ where $h_{t}^{1}$ is the CPS gross hiring flow from the pool of unemployment plus out of the labor force and $f_{t+i}$ is NFCB GDP $(f)$, in logged, HP filtered terms (see Appendix $C$ for data definitions and sources).

\section{Table 3 and Figure 1}

Hiring rates from non-employment are counter-cyclical. This fact has received little attention in the literature.

\subsection{Job to Job Flows}

I repeat the same computation for job to job flows i.e., $\rho\left(\frac{h_{t}^{2}}{n_{t}}, f_{t+i}\right)$ where $h_{t}^{2}$ is the CPS gross job to job flows, based on the work of Fallick and Fleischmann (2004), which was updated till 2013 (see Appendix C). The sample here starts in 1994.

\section{Table 4 and Figure 2}

Job to job flows, i.e., hiring rates from employment, are pro-cyclical. This is well-known; see, for example, Davis, Faberman, and Haltiwanger (2012, pp.14-15).

\subsection{Vacancy Rates}

I repeat the same computation for vacancy rates i.e., $\rho\left(\frac{v_{t}}{n_{t}}, f_{t+i}\right)$ where $v_{t}$ is the adjusted HWI rate taken from Barnichon (2014), as delineated in the Appendix C.

\section{Table 5 and Figure 3}

Vacancy rates are pro-cyclical, as is well-known too (see Davis, Faberman and Haltiwanger (2013)).

\subsection{CPS vs JOLTS Hires Data}

When using these worker flows, a natural question that arises concerns the possible use of JOLTS data. These data are not used here, as they do not allow for the breakdown of hiring into $h_{t}^{1}$ and $h_{t}^{2}$ and are available only from December 2000 (for a detailed discussion of these data see Davis, Faberman 
and Haltiwanger (2013)). Moreover, there are big differences between CPS and JOLTS data as shown in the following table that pertains to total hires $h_{t}=h_{t}^{1}+h_{t}^{2}$ in the overlapping sample period.

\section{Table 6}

The following conclusions emerge from the table: the CPS mean is 1.83 times higher that the JOLTS mean, the CPS median is 1.81 times higher; the c.o.v of CPS is 0.0587 , about half of c.o.v for JOLTS at 0.10; the third moment is very different; only the fourth moment is close across the data samples.

Hence one should note that these two data sets yield very different worker flow series and any comparisons need to be done with care. I do not use JOLTS data here for the reasons elaborated above (for further discussion,see Davis, Faberman and Haltiwanger (2006)).

\subsection{Consistency with Well-Known Facts}

The emerging picture from Figures 1-3 and Tables 3-5 is consistent with some well-known facts. Note that the hiring rate is the product of the job finding rate, the non-employment rate and the inverse of the employment rate:

$$
\underbrace{\frac{h_{t}^{1}}{n_{t}}}_{\text {hiring rate }}=\underbrace{\frac{h_{t}^{1}}{u_{t}+o_{t}}}_{\text {job finding }} \times \underbrace{\frac{u_{t}+o_{t}}{p o p_{t}}}_{\text {non-emp }} \times \underbrace{\frac{1}{\frac{n_{t}}{p o p_{t}}}}_{\text {inv emp ratio }}
$$

where pop is the working age population.

The following table shows the co-movement statistics for these variables.

\section{Table 7}

The job finding rate $\frac{h_{t}^{1}}{u_{t}+o_{t}}$ is pro-cyclical, as is well known. The latter feature has been emphasized by Shimer (2012). The non-employment rate $\frac{u_{t}+o_{t}}{p o p_{t}}$ and the inverse of the employment ratio $\frac{1}{\frac{n_{t}}{p o p_{t}}}$ are counter-cyclical, as widely known too. At the same time the gross hiring rate $\frac{h_{t}^{1}}{n_{t}}$ is countercyclical, as shown above. The hiring rate is counter-cyclical as the countercyclicality of the last two variables dominates the pro-cyclicality of the jobfinding rate. ${ }^{7}$

Also note the following. Employment dynamics are given by:

$$
\frac{n_{t+1}-n_{t}}{n_{t}}=\frac{h_{t}^{1}}{n_{t}}-\psi_{t}^{1}
$$

\footnotetext{
${ }^{7}$ In this context the following quote from Shimer (2012, page 145) is pertinent: "Still, it is most important point to recognize the differential behavior of the job finding probability and the number of workers finding jobs;..."
} 
Along the cycle the variables in (26) can be shown as follows:

\section{Figure 4}

Evidently, in the shaded NBER-dated recession periods, net employment growth is negative with separations being higher than hires. At the same time, in cyclical terms, Figure 5 shows that both rates increase - relative to the HP trend - during recessions, i.e., both are counter-cyclical.

Figure 5

\section{Results}

I present GMM estimates of equations (15) and (16) under the alternative specifications described above. Subsequently I use the estimates to present the variance decomposition defined in (24) and a graphical illustration of key relationships as implied by estimation.

\subsection{FOC Estimation}

Table 8 reports the results of estimation. The table reports the estimates and their standard errors, Hansen's (1982) J-statistic and its p-value.

\section{Table 8}

Table 9 shows the moments of the estimated marginal costs series.

\section{Table 9}

Row (a) examines a quadratic function $\left(\eta_{1}=\eta_{2}=2\right)$ with linear interactions $\left(\eta_{31}=\eta_{32}=1\right)$. The weights on the different elements of the hiring process - vacancies, hiring from non-employment, and hiring from other employment - are expressed by the fixed parameters $\lambda_{1}=0.6, \lambda_{2}=0.2$, obtained after some experimentation. The parameters estimated are the scale parameters $\left(e_{1}, e_{2}, e_{31}\right.$ and $\left.e_{32}\right)$ of the frictions function (17) and the labor share $(\alpha)$ of the production function (20). The J-statistic has a high p-value, the parameters are precisely estimated, and the resulting $g$ function fulfills all convexity requirements; the estimate of $\alpha$ is around the conventional estimate of 0.66 . Table 9 indicates very moderate costs estimates.

Row (b) takes up a very similar specification but ignores job to job flows, i.e., sets $\lambda_{2}=e_{32}=0$ and $h_{t}^{2}=\psi_{t}^{2}=0$. This allows for the use of a much longer data sample - 1976:1-2013:4, with 152 quarterly observations. It too yields a J-statistic with a high p-value, is, for the most part, precisely estimated, and the resulting $g$ fulfills all convexity requirements. 
The two rows - (a) and (b) - yield similar results in terms of the implied costs reported in Table 9. In particular, both feature negative coefficients for the interaction terms, implying complementarity between hiring and investment.

Row (c) follows Tobin's q type of models and looks at a quadratic specification, ignoring the other factor of production (here ignoring investment in capital). It thus sets $\eta_{2}=2, e_{1}=e_{31}=e_{32}=0$, i.e., has quadratic vacancy and hiring costs, with no role for capital (see equation (18)). While the results appear reasonable and there is no rejection of the model, this specification implies very high, unreasonable costs, as seen in Table 9. This is reminiscent of the results of Tobin'q models for investment.

Row (d) reports the results of the standard (Pissarides-type) search and matching model formulation with linear vacancy costs and no other arguments, as formulated in equation (19), such that $\eta_{2}=1, e_{1}=e_{31}=e_{32}=$ $\lambda_{1}=\lambda_{2}=0$. The emerging estimates imply even higher costs (shown in Table 9) and the parameter $\alpha$ is estimated at a high value (0.77).

In what follows I denote the results of row (a) as the preferred specification, noting that row (b) yields a similar picture over a longer sample period. I focus on row (a) so as to continue to take into account job to job flows, available only from 1994.

\subsection{Post Estimation: Approximation and Variance Decomposition}

Table 10 reports the results of the variance decomposition defined by equation (24) following the approximation equation (22).

Table 10

For the preferred specification, Table 10 shows that the key determinant of job value volatility (denoted $\operatorname{var}\left(P V_{t}\right)$ ) is the last term, i.e., the sum of the co-variances of job values with future marginal profits $\sum_{j=1}^{T}(\Omega)^{j-1} \operatorname{cov}\left(P V_{t}, M P_{t+j}\right)$. Recall that marginal profits $M P_{t+j}$ are net marginal productivity less the wage, $\left.\left(1-\tau_{t+j}\right)\left(\alpha-\frac{g_{n_{t+j}}}{\frac{f_{t+j}}{n_{t+j}}}-\frac{w_{t+j}}{\frac{f_{t+j}}{n_{t+j}}}\right)\right)$. With the small variability of $\tau_{t+j}$ and $\frac{g_{n_{t+j}}}{\frac{f_{t+j}}{n_{t+j}}}$, the main driver of volatility are the future labor shares $\frac{w_{t+j}}{\frac{f_{t+j}}{n_{t+j}}}$. All other terms in the decomposition play a very small role.

For the Tobin'q specification and for the standard search and matching model, Table 10 shows that there is some role in the variance decomposition also for the discount rate, the productivity growth rate and the separation rate. Together they account for about $20 \%$ of the variance of the approximated, truncated present value, as compared to less than $2 \%$ in the 
preferred specification. This difference helps explain some further implications of the estimates, discussed below.

\subsection{Implications for Key Relationships}

I look at the implications of the preferred specification for key relationships in the model. One such relationship is that of vacancy rates $\left(\frac{v_{t}}{n_{t}}\right)$ with job values $\left(\frac{Q_{t}^{N}}{\frac{f_{t}}{n_{t}}}\right)$ and investment rates $\left(\frac{i_{t}}{k_{t}}\right)$. Using equation (13) and the estimates of row (a) in Table 8 this is given by:

$$
\frac{v_{t}}{n_{t}}=\frac{\frac{\frac{e_{t}^{N}}{f_{t}}\left(q_{t}^{1}+q_{t}^{2}\right)}{\left(1-\tau_{t}\right)}-\left(e_{31} q_{t}^{1}+e_{32} q_{t}^{2}\right) \frac{i_{t}}{k_{t}}}{e_{2}\left[\left(1-\lambda_{1}-\lambda_{2}\right)+\lambda_{1} q_{t}^{1}+\lambda_{2} q_{t}^{2}\right]^{2}}
$$

This equation is plotted in Figure 6, using the sample averages of tax rates $\left(\tau_{t}\right)$ and job filling rates $\left(q_{t}^{1}, q_{t}^{2}\right)$ employing the point estimates of the preferred specification. The figure uses empirically-relevant ranges for $\frac{v_{t}}{n_{t}}$, shown on the vertical axis, and $\frac{Q_{t}^{N}}{\frac{f_{t}}{n_{t}}}$ and $\frac{i_{t}}{k_{t}}$, shown on the horizontal axes.

\section{Figure 6}

This is a linear relationship, whereby labor recruiting, as expressed by the vacancy rate, rises with job values and with the other firm activity the capital investment rate. In the following sections I look at the cyclical behavior and volatility of these three key variables $-\frac{v_{t}}{n_{t}}, \frac{Q_{t}^{N}}{\frac{f_{t}}{n_{t}}}$ and $\frac{i_{t}}{k_{t}}$.

Another such relationship is the one between vacancy rates $\left(\frac{v_{t}}{n_{t}}\right)$ and the job filling rates $\left(q_{t}^{1}, q_{t}^{2}\right)$ which the firm faces. These job-filling rates express the influence of matching processes and market conditions, taken as given by the firm. Using equation (27), the estimates of row (a) in Table 8, and the sample averages of $\tau_{t}, \frac{Q_{t}^{N}}{\frac{f_{t}}{n_{t}}}$ and $\frac{i_{t}}{k_{t}}$ this is shown in Figure 7.

\section{Figure 7}

This is a non-linear relationship. The figure shows a non-trivial asymmetry: recruiting $\left(\frac{v_{t}}{n_{t}}\right)$ falls as the job filling rate from non-employment $\left(q_{t}^{1}\right)$ rises, and rises as the job filling rate from other firms $\left(q_{t}^{2}\right)$ rises. Why so? Each job filling rate has three effects. One is to increase the job value through the term $\frac{\frac{Q_{t}^{N}}{f_{t}}\left(q_{t}^{1}+q_{t}^{2}\right)}{\left(1-\tau_{t}\right)}$ thereby increasing the vacancy rate. A second is to reduce marginal costs via the interaction with the rate of investment, i.e., the term $-\left(e_{31} q_{t}^{1}+e_{32} q_{t}^{2}\right) \frac{i_{t}}{k_{t}}$ which also operates to increase the vacancy 
rate (note that $e_{31}, e_{32}<0$ ). The third is a scale effect that raises marginal costs for any level of the vacancy rate, i.e., the term $\left.e_{2}\left[\left(1-\lambda_{1}-\lambda_{2}\right)+\lambda_{1} q_{t}^{1}+\lambda_{2} q_{t}^{2}\right]^{2}\right)$. This third effect operates to lower the vacancy rate. The preferred specification implies that the third effect dominates in the case of the job filling rate from non-employment $\left(q_{t}^{1}\right)$ and the first two effects dominate in the case of the job filling rate from other firms $\left(q_{t}^{2}\right)$.

\section{The Cyclicality of Job Values}

Section 5 above has presented the cyclical properties of the key data series. This section examines the cyclical properties of estimated job values in the different models.

Table 11 reports the cyclical behavior of estimated job values, using the point estimates of the LHS of equation (16), i.e., of marginal hiring costs, as reported in the different specifications of Table 8 . Figure 8 presents the time series plots.

\section{Table 11 and Figure 8}

The preferred specification (row (a) of Table 8) indicates counter-cyclicality, the Tobin's q model is weakly pro-cyclical (row (c)), while the standard model (row (d)) is strongly pro-cyclical.

Getting back to equation (1) the implications of these results are that they indicate very different views of the cyclicality of job values.

Starting with the specification of row (d) in Table 8, the standard search and matching (Pissarides-type) model, note that in its simple form the optimality equation is given by (re-writing equation (19)):

$$
\left(1-\tau_{t}\right) \frac{e_{2}}{q_{t}}=E_{t}\left[\rho_{t+1}\left(1-\tau_{t+1}\right) \frac{\frac{f_{t+1}}{n_{t+1}}}{\frac{f_{t}}{n_{t}}}\left[\alpha-\frac{w_{t+1}}{\frac{f_{t+1}}{n_{t+1}}}+\left(1-\psi_{t+1}\right) \frac{e_{2}}{q_{t+1}}\right]\right]
$$

This equation has a pro-cyclical $M C_{t}$ on the LHS, as shown in Table 11 and Figure 8. This is to be expected as it depends inversely on the matching rate $q_{t}=\frac{h_{t}}{v_{t}}$, which itself is highly counter-cyclical. This means that job values, on the RHS, are pro-cyclical too.

The specification of row (c) in Table 8, the Lucas-Prescott/Tobin approach has marginal costs being weakly pro-cyclical, as seen in Table 11 and Figure 8. Repeating equation (18):

$$
\left(1-\tau_{t}\right) \frac{e_{2}}{q_{t}}\left[\begin{array}{c}
\left(1-\lambda_{1}-\lambda_{2}\right) \\
+\lambda_{1} q_{t}^{1}+\lambda_{2} q_{t}^{2}
\end{array}\right]^{2} \frac{v_{t}}{n_{t}}=E_{t} \frac{1}{\frac{f_{t}}{n_{t}}}\left[\rho_{t, t+1}\left(1-\tau_{t+1}\right)\left[\begin{array}{c}
f_{n_{t+1}}-g_{n_{t+1}}-w_{t+1} \\
+\left(1-\psi_{t+1}\right) \frac{g_{v_{t+1}}}{q_{t+1}}
\end{array}\right]\right]
$$


The reason for the weak pro-cyclicality is that the pro-cyclicality of $\frac{e_{2}}{q_{t}}$ and of $\frac{v_{t}}{n_{t}}$ is offset to some extent by the counter-cyclicality of $q_{t}^{1}$ and $q_{t}^{2}$.

The preferred specification of row (a) in Table 8, implies the opposite. The results of Table 11 and Figure 8 indicate counter-cyclicality. Note that this is a broader model. It follows the Pissarides approach of using a vacancy creation equation but $M C_{t}$ depends on all the relevant rates $-\frac{h_{t}^{1}}{n_{t}}, \frac{h_{t}^{2}}{n_{t}}$ and $\frac{v_{t}}{n_{t}}$. The equation here is:

$$
\left(1-\tau_{t}\right) \frac{1}{q_{t}}\left[\begin{array}{c}
e_{2}\left[\begin{array}{c}
\left(1-\lambda_{1}-\lambda_{2}\right) \\
+\lambda_{1} q_{t}^{1}+\lambda_{2} q_{t}^{2} \\
+\left(e_{31} q_{t}^{1}+e_{32} q_{t}^{2}\right)
\end{array}\right]^{2} \frac{v_{t}}{k_{t}}
\end{array}\right]=E_{t} \frac{1}{\frac{f_{t}}{n_{t}}}\left[\rho_{t, t+1}\left(1-\tau_{t+1}\right)\left[\begin{array}{c}
f_{n_{t+1}}-g_{n_{t+1}}-w_{t+1} \\
+\left(1-\psi_{t+1}\right) \frac{g_{v_{t+1}}}{q_{t+1}}
\end{array}\right]\right]
$$

This model delivers counter-cyclicality on both sides of the equation, as the pro-cyclicality of $\frac{1}{q_{t}} \frac{v_{t}}{n_{t}}$, and of $\left(e_{31} q_{t}^{1}+e_{32} q_{t}^{2}\right) \frac{i_{t}}{k_{t}}$ is out-weighed by the counter-cyclical term $\left[\left(1-\lambda_{1}-\lambda_{2}\right)+\lambda_{1} q_{t}^{1}+\lambda_{2} q_{t}^{2}\right]^{2}$.

Note,too, that the RHS of equations (28), (29) and (30) are not the same. Table 10 gave evidence of that in terms of the variance decomposition.

\section{The Volatility of Recruitment Rates}

The focus so far has been on the cyclicality of recruiting and of the associated job values. In this section I turn to study the volatility of the key variables expressing recruitment behavior, using the estimation results. In particular, I seek to explain the finding of high volatility, which has been widely discussed in the literature, mostly following Shimer (2005). I start by presenting some pertinent data moments. I then do variance decompositions of the vacancy rate, the total hiring rate, and the rate of hiring from non-employment using the preferred estimates, and of the vacancy rate, using the estimates of the standard search and matching model. I conclude by summarizing the findings with respect to the determinants of the high volatility of these recruitment variables.

\subsection{Background Data Moments}

As a background for the analysis to follow consider the following data moments. Table 12a shows the volatility, in terms of the standard deviations, of the key variables in firm behavior: the hiring rate - both the total one $\frac{h_{t}}{n_{t}}$ and the rate from non-employment $\frac{h_{t}^{1}}{n_{t}}$, the vacancy rate $\frac{v_{t}}{n_{t}}$, and the job filling rates $q_{t}^{1}$ and $q_{t}^{2}$. I also look at the investment rate $\frac{i_{t}}{k_{t}} .8$ Table $12 \mathrm{~b}$ presents

\footnotetext{
${ }^{8}$ The discussion here complements the discussion in Section 5 above. All variables are logged and HP-filtered.
} 
the standard deviation and correlation of two key determinants: output (NFCB GDP, $f$ ) and the tax-adjusted job value $\left(\frac{Q_{t}^{N}}{\left(1-\tau_{t}\right) \frac{f_{t}}{n_{t}}}\right)$, as estimated in Table 8 row (a). Table 12c reports the co-movement of the firm variables and the two latter variables.

\section{Tables 12 a,b,c}

These series are shown in Figure 9 with the vertical lines indicating the start and end of NBER-dated recessions.

\section{Figure 9}

The following points may be noted:

(i) The vacancy rate and the job filling rates are much more volatile than the hiring rates. As the latter are a function of the former, i.e., $\frac{h_{t}}{n_{t}}=\left(q_{t}^{1}+\right.$ $\left.q_{t}^{2}\right) \frac{v_{t}}{n_{t}}$, this is the result of the negative co-movement of $\frac{v_{t}}{n_{t}}$ and $\left(q_{t}^{1}+q_{t}^{2}\right)$.

(ii) Job values are much more volatile than output and are negatively correlated with it, i.e., are countercyclical.

(iii) In terms of the business cycle, the well-known moments shown here are the pro-cyclicality of the investment rate and of the vacancy rate and the counter-cyclicality of job filling rates. Much less known is the weak cyclicality of hiring rates, with the rate of hiring from non-employment, actually being counter-cyclical, as discussed in Section 5 .

(iv) Job values have positive co-movement with the worker flow from non-employment, as expressed by the hiring rate $\frac{h_{t}^{1}}{n_{t}}$ and the job filling rate $q_{t}^{1}$. But they negatively co-move with the decision variables of the firm vacancy and investment rates.

These moments suggest differential behavior of the various recruitment variables, which I analyze using variance decompositions.

\subsection{The Vacancy Rate}

To explain the volatility of the vacancy rate, I start off from the F.O.C:

$$
\left(1-\tau_{t}\right) \frac{g_{v_{t}}}{q_{t} \frac{f_{t}}{n_{t}}}=\frac{Q_{t}^{N}}{\frac{f_{t}}{n_{t}}}
$$

Using the preferred estimates of Table 8 row (a) I get:

$$
\frac{1}{q_{t}^{1}+q_{t}^{2}}\left[\begin{array}{c}
e_{2}\left[\left(1-\lambda_{1}-\lambda_{2}\right)+\lambda_{1} q_{t}^{1}+\lambda_{2} q_{t}^{2}\right]^{2} \frac{v_{t}}{n_{t}} \\
+\left(e_{31} q_{t}^{1}+e_{32} q_{t}^{2}\right) \frac{i_{t}}{k_{t}}
\end{array}\right]=\frac{Q_{t}^{N}}{\left(1-\tau_{t}\right) \frac{f_{t}}{n_{t}}}
$$

The vacancy rate can then be expressed as follows (basically re-writing equation (27)): 


$$
\begin{aligned}
\frac{v_{t}}{n_{t}}= & \frac{\frac{Q_{t}^{N}}{\left(1-\tau_{t}\right) \frac{f_{t}}{n_{t}}}\left(q_{t}^{1}+q_{t}^{2}\right)}{e_{2}\left[\left(1-\lambda_{1}-\lambda_{2}\right)+\lambda_{1} q_{t}^{1}+\lambda_{2} q_{t}^{2}\right]^{2}} \\
& -\frac{\left(e_{31} q_{t}^{1}+e_{32} q_{t}^{2}\right) \frac{i_{t}}{k_{t}}}{e_{2}\left[\left(1-\lambda_{1}-\lambda_{2}\right)+\lambda_{1} q_{t}^{1}+\lambda_{2} q_{t}^{2}\right]^{2}}
\end{aligned}
$$

Equation (31) shows that the vacancy rate is composed of two terms:

(i) The job value $\frac{Q_{t}^{N}}{\left(1-\tau_{t}\right) \frac{f_{t}}{n_{t}}}$, multiplied by a factor $\frac{\left(q_{t}^{1}+q_{t}^{2}\right)}{e_{2}\left[\left(1-\lambda_{1}-\lambda_{2}\right)+\lambda_{1} q_{t}^{1}+\lambda_{2} q_{t}^{2}\right]^{2}}$, which is a non-linear function of the job filling rates $q_{t}^{1}$ and $q_{t}^{2}$ and model parameters $\left(e_{2}, \lambda_{1}, \lambda_{2}\right)$.

(ii) The investment rate $\frac{i_{t}}{k_{t}}$, multiplied by another factor $\frac{-\left(e_{31} q_{t}^{1}+e_{32} q_{t}^{2}\right)}{e_{2}\left[\left(1-\lambda_{1}-\lambda_{2}\right)+\lambda_{1} q_{t}^{1}+\lambda_{2} q_{t}^{2}\right]^{2}}$, which is a (different) non-linear function of the job filling rates $q_{t}^{1}$ and $q_{t}^{2}$ and model parameters $\left(e_{2}, e_{31}, e_{32}, \lambda_{1}, \lambda_{2}\right)$.

Table 13 reports the following variance decomposition which ensues:

$$
\begin{aligned}
\operatorname{var}\left(\frac{v_{t}}{n_{t}}\right)= & \operatorname{var}\left(\frac{\frac{Q_{t}^{N}}{\left(1-\tau_{t}\right) \frac{f_{t}}{n_{t}}}\left(q_{t}^{1}+q_{t}^{2}\right)}{e_{2}\left[\left(1-\lambda_{1}-\lambda_{2}\right)+\lambda_{1} q_{t}^{1}+\lambda_{2} q_{t}^{2}\right]^{2}}\right) \\
& +\operatorname{var}\left(\frac{\left(e_{31} q_{t}^{1}+e_{32} q_{t}^{2}\right) \frac{i_{t}}{k_{t}}}{e_{2}\left[\left(1-\lambda_{1}-\lambda_{2}\right)+\lambda_{1} q_{t}^{1}+\lambda_{2} q_{t}^{2}\right]^{2}}\right) \\
& -2 \operatorname{cov}\left(\frac{\frac{Q_{t}^{N}}{\left(1-\tau_{t}\right) \frac{f_{t}}{n_{t}}}\left(q_{t}^{1}+q_{t}^{2}\right)}{e_{2}\left[\left(1-\lambda_{1}-\lambda_{2}\right)+\lambda_{1} q_{t}^{1}+\lambda_{2} q_{t}^{2}\right]^{2}}, \frac{\left(e_{31} q_{t}^{1}+e_{32} q_{t}^{2}\right) \frac{i_{t}}{k_{t}}}{e_{2}\left[\left(1-\lambda_{1}-\lambda_{2}\right)+\lambda_{1} q_{t}^{1}+\lambda_{2} q_{t}^{2}\right]^{2}}\right)
\end{aligned}
$$

Table 13

The table implies that by far the biggest part of the variance of vacancy rates can be attributed to its second term, i.e., to investment rates $\frac{i_{t}}{k_{t}}$ multiplied by the factor delineated above. Note that this term becomes zero in the case of no interaction of hiring costs and investment costs $\left(e_{31}=e_{32}=\right.$ $0)$.

In order to better understand the significance of this breakdown, Table 14 shows correlations of these two terms with GDP $\left(f_{t}\right)$ and with job values $\left(\frac{Q_{t}^{N}}{\left(1-\tau_{t}\right) \frac{f_{t}}{n_{t}}}\right)$, where all variables have been logged and HP-filtered:

\section{Table 14}


Vacancy rates are pro-cyclical (0.91) and are negatively correlated (-0.56) with job values. This pro-cyclicality, as well as the negative correlation with job values, is very much engendered by the correlations of the second term, the investment rate multiplied by a factor, with GDP and with job values. In contrast, the first term determining the vacancy rate, job values multiplied by a factor, is weakly pro-cyclical and has a positive, rather than negative, correlation with job values.

Hence the second moments of the vacancy rate are dominated by the interaction of hiring and investment costs. The latter are a function of investment rates, which are volatile and pro-cyclical, as reported in Tables $12 \mathrm{a}$ and c above. It is this vacancy rate which has been, together with the unemployment rate, at the center of attention in the discussions of high labor market volatility following Shimer (2005). The analysis here points to a volatility determinant which has received little, if any, attention previously: the capital investment rate operating through the interaction of investment and hiring costs.

\subsection{The Total Hiring Rate}

I now study the hiring rate in the same way. Note that the total hiring rate $\frac{h_{t}}{n_{t}}$ is given by:

$$
\begin{aligned}
\frac{h_{t}}{n_{t}}= & \left(q_{t}^{1}+q_{t}^{2}\right) \frac{v_{t}}{n_{t}}=\frac{\frac{Q_{t}^{N}}{\left(1-\tau_{t}\right) \frac{f_{t}}{n_{t}}}\left(q_{t}^{1}+q_{t}^{2}\right)^{2}}{e_{2}\left[\left(1-\lambda_{1}-\lambda_{2}\right)+\lambda_{1} q_{t}^{1}+\lambda_{2} q_{t}^{2}\right]^{2}} \\
& -\frac{\left(q_{t}^{1}+q_{t}^{2}\right)\left(e_{31} q_{t}^{1}+e_{32} q_{t}^{2}\right) \frac{i_{t}}{k_{t}}}{e_{2}\left[\left(1-\lambda_{1}-\lambda_{2}\right)+\lambda_{1} q_{t}^{1}+\lambda_{2} q_{t}^{2}\right]^{2}}
\end{aligned}
$$

I repeat the same computations for hiring rates. The variance of hiring rate is given by:

$$
\begin{aligned}
\operatorname{var}\left(\frac{h_{t}}{n_{t}}\right)= & \operatorname{var}\left(\frac{\frac{Q_{t}^{N}}{\left(1-\tau_{t}\right) \frac{f_{t}}{n_{t}}}\left(q_{t}^{1}+q_{t}^{2}\right)^{2}}{e_{2}\left[\left(1-\lambda_{1}-\lambda_{2}\right)+\lambda_{1} q_{t}^{1}+\lambda_{2} q_{t}^{2}\right]^{2}}\right) \\
& +\operatorname{var}\left(\frac{\left(q_{t}^{1}+q_{t}^{2}\right)\left(e_{31} q_{t}^{1}+e_{32} q_{t}^{2}\right) \frac{i_{t}}{k_{t}}}{e_{2}\left[\left(1-\lambda_{1}-\lambda_{2}\right)+\lambda_{1} q_{t}^{1}+\lambda_{2} q_{t}^{2}\right]^{2}}\right) \\
& -2 \operatorname{cov}\left(\frac{\frac{Q_{t}^{N}}{\left(1-\tau_{t}\right) \frac{f_{t}}{n_{t}}}\left(q_{t}^{1}+q_{t}^{2}\right)^{2}}{e_{2}\left[\left(1-\lambda_{1}-\lambda_{2}\right)+\lambda_{1} q_{t}^{1}+\lambda_{2} q_{t}^{2}\right]^{2}}, \frac{\left(q_{t}^{1}+q_{t}^{2}\right)\left(e_{31} q_{t}^{1}+e_{32} q_{t}^{2}\right) \frac{i_{t}}{k_{t}}}{e_{2}\left[\left(1-\lambda_{1}-\lambda_{2}\right)+\lambda_{1} q_{t}^{1}+\lambda_{2} q_{t}^{2}\right]^{2}}\right)
\end{aligned}
$$

This yields the following decomposition in Table 15: 
Table 15

The table implies that by far the bigger part of the variance of hiring rates can again be attributed to its second term, i.e., investment rates $\frac{i_{t}}{k_{t}}$ multiplied by a factor $\frac{\left(q_{t}^{1}+q_{t}^{2}\right)\left(e_{31} q_{t}^{1}+e_{32} q_{t}^{2}\right)}{e_{2}\left[\left(1-\lambda_{1}-\lambda_{2}\right)+\lambda_{1} q_{t}^{1}+\lambda_{2} q_{t}^{2}\right]^{2}}$ which is a non-linear function of the job filling rates $q_{t}^{1}$ and $q_{t}^{2}$ and model parameters $\left(e_{2}, e_{31}, e_{32}, \lambda_{1}, \lambda_{2}\right)$. This term, again, is zero in the case of no interaction of hiring costs and investment costs $\left(e_{31}=e_{32}=0\right)$.

Table 16 shows the correlations of the two components of $\frac{h_{t}}{n_{t}}$ with GDP $\left(f_{t}\right)$ and with job values $\left(\frac{Q_{t}^{N}}{\left(1-\tau_{t}\right) \frac{f_{t}}{n_{t}}}\right)$, where all variables have been logged and HP-filtered:

\section{Table 16}

Here hiring is weakly related to GDP and to job values. Its two constituent terms offset each other, hence the weak correlations.

\subsection{The Rate of Hiring from Non-Employment}

Turning now to a sub-set of total hiring, the hiring rate from non-employment, it is given by:

$$
\begin{aligned}
\frac{h_{t}^{1}}{n_{t}}= & q_{t}^{1} \frac{v_{t}}{n_{t}}=\frac{\frac{Q_{t}^{N}}{\left(1-\tau_{t}\right) \frac{f_{t}}{n_{t}}}\left(q_{t}^{1}+q_{t}^{2}\right) q_{t}^{1}}{e_{2}\left[\left(1-\lambda_{1}-\lambda_{2}\right)+\lambda_{1} q_{t}^{1}+\lambda_{2} q_{t}^{2}\right]^{2}} \\
& -\frac{q_{t}^{1}\left(e_{31} q_{t}^{1}+e_{32} q_{t}^{2}\right) \frac{i_{t}}{k_{t}}}{e_{2}\left[\left(1-\lambda_{1}-\lambda_{2}\right)+\lambda_{1} q_{t}^{1}+\lambda_{2} q_{t}^{2}\right]^{2}}
\end{aligned}
$$

Thus:

$$
\begin{aligned}
\operatorname{var}\left(\frac{h_{t}^{1}}{n_{t}}\right)= & \operatorname{var}\left(\frac{\frac{Q_{t}^{N}}{\left(1-\tau_{t}\right) \frac{f_{t}}{n_{t}}}\left(q_{t}^{1}+q_{t}^{2}\right) q_{t}^{1}}{e_{2}\left[\left(1-\lambda_{1}-\lambda_{2}\right)+\lambda_{1} q_{t}^{1}+\lambda_{2} q_{t}^{2}\right]^{2}}\right) \\
& +\operatorname{var}\left(\frac{q_{t}^{1}\left(e_{31} q_{t}^{1}+e_{32} q_{t}^{2}\right) \frac{i_{t}}{k_{t}}}{e_{2}\left[\left(1-\lambda_{1}-\lambda_{2}\right)+\lambda_{1} q_{t}^{1}+\lambda_{2} q_{t}^{2}\right]^{2}}\right) \\
& -2 \operatorname{cov}\left(\frac{\frac{Q_{t}^{N}}{\left(1-\tau_{t}\right) \frac{f_{t}}{n_{t}}}\left(q_{t}^{1}+q_{t}^{2}\right) q_{t}^{1}}{e_{2}\left[\left(1-\lambda_{1}-\lambda_{2}\right)+\lambda_{1} q_{t}^{1}+\lambda_{2} q_{t}^{2}\right]^{2}}, \frac{q_{t}^{1}\left(e_{31} q_{t}^{1}+e_{32} q_{t}^{2}\right) \frac{i_{t}}{k_{t}}}{e_{2}\left[\left(1-\lambda_{1}-\lambda_{2}\right)+\lambda_{1} q_{t}^{1}+\lambda_{2} q_{t}^{2}\right]^{2}}\right)
\end{aligned}
$$

This yields the following decomposition in Table 17: 


\section{Table 17}

Here it is the first term, which depends on the job value, which plays the bigger role.

Table 18 shows the correlations of the two components of $\frac{h_{t}^{1}}{h_{t}}$ with GDP $\left(f_{t}\right)$ and with job values $\left(\frac{Q_{t}^{N}}{\left(1-\tau_{t}\right) \frac{f_{t}}{n_{t}}}\right)$, where all variables have been logged and HP-filtered:

\section{Table 18}

The dominant role of the job value term is seen here by the correlation of the hiring rate $\left(\frac{h_{t}^{1}}{n_{t}}\right)$ with it, 0.78 , and by the fact that the hiring rate is counter-cyclical, following the counter-cyclicality of job values.

Note that the results of Tables 17 and 18, where job values dominate, are almost the opposite of the results of Tables 13 and 14 with respect to the vacancy rate and the results of Tables 15 and 16 with respect to the total hiring rate, where the interaction with investment rates dominates.

\subsection{The Standard Search and Matching Model.}

Now consider the same analysis in terms of the standard search and matching model. The relevant equation is:

$$
\left(1-\tau_{t}\right) \frac{g_{v_{t}}}{q_{t} \frac{f_{t}}{n_{t}}}=\frac{Q_{t}^{N}}{\frac{f_{t}}{n_{t}}}
$$

which in this case is given by:

$$
\left(1-\tau_{t}\right) \frac{e_{2}}{q_{t}}=\frac{Q_{t}^{N}}{\frac{f_{t}}{n_{t}}}
$$

Employing the widely-used Cobb Douglas matching function I get:

$$
\begin{aligned}
\frac{m_{t}}{n_{t}} & =\mu\left(\frac{v_{t}}{n_{t}}\right)^{\sigma}\left(\frac{u_{t}}{n_{t}}\right)^{1-\sigma} \\
q_{t} & =\frac{m_{t}}{v_{t}}=\frac{m_{t}}{n_{t}} \frac{n_{t}}{v_{t}} \\
& =\mu\left(\frac{v_{t}}{n_{t}}\right)^{\sigma-1}\left(\frac{u_{t}}{n_{t}}\right)^{1-\sigma}
\end{aligned}
$$

So:

$$
\left(1-\tau_{t}\right) \frac{e_{2}}{\mu\left(\frac{v_{t}}{n_{t}}\right)^{\sigma-1}\left(\frac{u_{t}}{n_{t}}\right)^{1-\sigma}}=\frac{Q_{t}^{N}}{\frac{f_{t}}{n_{t}}}
$$


Solving out for the vacancy rate:

$$
\begin{aligned}
\mu\left(\frac{v_{t}}{n_{t}}\right)^{\sigma-1} & =\left(1-\tau_{t}\right) \frac{e_{2}}{\left(\frac{u_{t}}{n_{t}}\right)^{1-\sigma} \frac{Q_{t}^{N}}{\frac{f_{t}}{n_{t}}}} \\
\frac{v_{t}}{n_{t}} & =\left[\frac{e_{2}}{\mu} \frac{\left(1-\tau_{t}\right)}{\left.\left(\frac{u_{t}}{n_{t}}\right)^{1-\sigma} \frac{Q_{t}^{N}}{\frac{f_{t}}{n_{t}}}\right]^{\frac{1}{\sigma-1}}}\right.
\end{aligned}
$$

In log terms this is given by:

$$
\ln \frac{v_{t}}{n_{t}}=\frac{1}{\sigma-1}\left[\ln \frac{e_{2}}{\mu_{t}}-\ln \left(\frac{u_{t}}{n_{t}}\right)^{1-\sigma}-\ln \left(\frac{Q_{t}^{N}}{\frac{f_{t}}{n_{t}}\left(1-\tau_{t}\right)}\right)\right]
$$

The variance decomposition is thus given by:

$$
\begin{aligned}
\operatorname{var}\left(\ln \frac{v_{t}}{n_{t}}\right)= & \left(\frac{1}{\sigma-1}\right)^{2} \operatorname{var}\left[\ln \frac{e_{2}}{\mu_{t}}\right] \\
& +\left(\frac{1}{\sigma-1}\right)^{2} \operatorname{var}\left[\ln \left(\frac{u_{t}}{n_{t}}\right)^{1-\sigma}\right] \\
& +\left(\frac{1}{\sigma-1}\right)^{2} \operatorname{var}\left[\ln \frac{Q_{t}^{N}}{\frac{f_{t}}{n_{t}}\left(1-\tau_{t}\right)}\right] \\
& -2\left(\frac{1}{\sigma-1}\right)^{2} \operatorname{cov}\left[\ln \frac{e_{2}}{\mu_{t}}, \ln \left(\frac{u_{t}}{n_{t}}\right)\right] \\
& -2\left(\frac{1}{\sigma-1}\right)^{2} \operatorname{cov}\left[\ln \frac{e_{2}}{\mu_{t}}, \ln \frac{Q_{t}^{N}}{\frac{f_{t}}{n_{t}}\left(1-\tau_{t}\right)}\right] \\
& +2\left(\frac{1}{\sigma-1}\right)^{2} \operatorname{cov}\left[\ln \left(\frac{u_{t}}{n_{t}}\right)^{1-\sigma}, \ln \frac{Q_{t}^{N}}{\frac{f_{t}}{n_{t}}\left(1-\tau_{t}\right)}\right]
\end{aligned}
$$

Table 19 reports it, using the estimates of Table 8 row (d).

\section{Table 19}

The dominant term is the job value term, though all terms are sizeable, except for the co-variance between job values and the matching technology.

Table 20 shows the correlations of the components of $\frac{v_{t}}{n_{t}}$ with GDP $\left(f_{t}\right)$ and with job values $\left(\frac{Q_{t}^{N}}{\left(1-\tau_{t}\right) \frac{f_{t}}{n_{t}}}\right)$, where all variables have been logged and HP-filtered. 
Vacancy rates are pro-cyclical and are positively correlated with job values, which are themselves pro-cyclical in this model (as discussed in Section 7 above).

\subsection{Summing Up}

The key series pertaining to worker recruiting display substantially different behavior.

(i) For both the vacancy rate $\frac{v_{t}}{n_{t}}$ and the total hiring rate $\frac{h_{t}}{n_{t}}$ the following is found:

a. There are two determinants: the job value $\frac{Q_{t}^{N}}{\left(1-\tau_{t}\right) \frac{f_{t}}{n_{t}}}$ multiplied by a factor, and the investment rate $\frac{i_{t}}{k_{t}}$ multiplied by a different factor, with each factor being a function of the job filling rates and model parameters. These factors are functions of market conditions.

b. Much of the variance comes from the term which depends on the investment rate, hence the interaction of hiring costs and investment costs is key.

c. Both are pro-cyclical due to the fact that the high pro-cyclicality of the investment rate term dominates the counter-cyclicality of the job value term.

(ii) The hiring rate from non-employment $\frac{h_{t}^{1}}{n_{t}}$ behaves differently, almost the opposite of the afore-going, and is counter-cyclical. It follows the behavior of job values, as the $\frac{Q_{t}^{N}}{\left(1-\tau_{t}\right) \frac{f_{t}}{n_{t}}}$ term dominates.

Hence the volatility of vacancy and total hiring rates is driven by capital investment behavior, while that of hiring from unemployment by the (different) behavior of job values.

(iii) In the volatility analysis of the standard search model, the job value term dominates and the vacancy rate is tightly linked to it.

\section{The Role of the Labor Share}

The labor share in GDP plays a key role in the afore-going results. It has also been the focus of some attention in recent macroeconomic models of the business cycle. The main reason for the key results of this paper is its cyclical behavior. The variance decomposition of the approximated $P V_{t}$ reported in Table 10 above reveals that the main determinant of the present value is the labor share; this is so because I am looking at the following expression (noting that all variables are computed relative to $\frac{f_{t+1}}{n_{t+1}}$ ): 


$$
\frac{f_{n_{t+1}}-g_{n_{t+1}}-w_{t+1}}{\frac{f_{t+1}}{n_{t+1}}}=\alpha-\left(\frac{g_{n_{t+1}}+w_{t+1}}{\frac{f_{t+1}}{n_{t+1}}}\right)
$$

As $\alpha$ is constant and the term $\frac{-g_{n_{t+1}}}{\frac{f_{t+1}}{n_{t+1}}}$ is empirically estimated to be small, the main driver is the labor share, $\frac{w_{t+1}}{\frac{f_{t+1}}{n_{t+1}}}$.

Consider the cyclicality of the labor share:

Table 21

Noting the bolded numbers in the table, dynamically, the labor share is pro-cyclical. As a result job values are counter-cyclical.

This cyclical behavior has recently been noted by a number of authors. The observation, whereby the labor share first falls in a boom and subsequently rises for a substantial period of time, i.e., is dynamically procyclical, was discussed by Rios-Rull and Santaeulalia-Llopis (2010). Hall (2014b) finds that the labor share is a-cyclical contemporaneously and procyclical subsequently. Ramey and Nekarda (2013) examine the cyclicality of mark-ups. Essentially they treat the mark-up as the inverse of the labor share (see their equation 5), allowing various modifications to the relationship, such as overhead hours, CES production functions, and differentials between marginal and average wages. Studying both aggregate and fourdigit manufacturing data of the U.S. economy, they find that mark-ups are contemporaneously pro-cyclical and that dynamically they are countercyclical. The latter finding means that if GDP is low now (recession), markups will rise henceforth (see their Figure 2). This is similar to the finding here that job values are counter-cyclical, i.e., that the present value of profits rises in recessions. It is so for the same reason, namely that the future labor share declines (i.e., again, dynamically the labor share is pro-cyclical).

Ramey and Nekarda (2013) also make the point that their findings contradict the conventional wisdom of New Keynesian models. The latter posit that demand shocks (monetary policy or government spending shocks) increase marginal costs while prices are sticky. Thereby positive shocks in these models lower the mark-ups, i.e., engender counter-cyclical mark-ups, contemporaneously, in contradiction to the afore-cited empirical findings.

\section{Explaining the Decline in Labor Market Fluidity}

Recently, Davis and Haltiwanger (2014) have documented a decline over time in U.S. labor market fluidity. They provide detailed evidence, in terms of both worker flows and job flows (see, in particular, their Figures 1-10). In terms of the variables in the current data set, this is manifested in the 
decline of $\frac{h^{1}}{n}, \frac{h^{2}}{n}, \psi^{1}, \psi^{2}$ and $\frac{v}{n}$, which can be seen in Figure 10 for the full sample period (noting that job to job flows are measured from 1994 only).

\section{Figure 10}

The afore-going analysis can account for these facts too. Consider the following equation derived from equation (13):

$$
\frac{Q_{t}^{N}}{\frac{f_{t}}{n_{t}}}=\left(1-\tau_{t}\right) \frac{g_{v_{t}}}{q_{t}^{1} \frac{f_{t}}{n_{t}}}
$$

Table 22 shows the estimated LHS and the RHS of equation (40) separately for two sub-periods. As it is hard to pinpoint one particular year as the dividing line, somewhat arbitrarily the following sub-periods were examined: 1976-1995 and 1996-2013. In order to cater for the longest sample period possible, the figure uses the preferred estimates of row (b) in Table 8. It uses point estimates for the parameter values and the estimated average job value $\frac{Q_{t}^{N}}{\frac{f_{t}}{n_{t}}}$ in each sub-sample. It also uses the data averages in the subsamples for the variables $\tau_{t}, q_{t}^{1}$ and $\frac{i_{t}}{k_{t}}$. Note that under this specification, which omits job to job flows, the RHS of equation (40) is given by (omitting time sub-scripts to denote averages):

$$
\begin{aligned}
(1-\tau) \frac{g_{v}}{q^{1} \frac{f}{n}} & =\frac{\left(1-\tau_{t}\right)}{q_{t}^{1}}\left(e_{2}\left(1-\lambda_{1}+\lambda_{1} q_{t}^{1}\right)^{2} \frac{v_{t}}{n_{t}}+e_{3} q_{t}^{1} \frac{i_{t}}{k_{t}}\right) \\
& =\left(1-\tau_{t}\right) e_{3} \frac{i_{t}}{k_{t}}+\frac{\left(1-\tau_{t}\right)}{q_{t}^{1}} e_{2}\left(1-\lambda_{1}+\lambda_{1} q_{t}^{1}\right)^{2} \frac{v_{t}}{n_{t}}
\end{aligned}
$$

\section{Table 22}

Figure 11 plots the LHS and RHS of equation (41) in the space of MC and PV on the vertical axis and vacancy rates $\frac{v}{n}$ on the horizontal axis.

\section{Figure 11}

The table and the figure show that job values $\left(\frac{Q^{N}}{\frac{f}{n}}\right)$ - depicted as the horizontal lines in the figure - declined somewhat going from the pre1995 period to the post-1995 period. The upward sloping curve, expressing marginal costs $\left((1-\tau) \frac{g_{v}}{q^{1 \frac{f}{n}}}\right)$, moved in a counter-clockwise fashion. The changes in this latter curve are as follows: its intercept $\left(1-\tau_{t}\right) e_{3} \frac{i_{t}}{k_{t}}$ declined as the tax rate fell and the investment rate increased, noting that $e_{3}<0$; its slope $\frac{\left(1-\tau_{t}\right)}{q_{t}^{1}} e_{2}\left(1-\lambda_{1}+\lambda_{1} q_{t}^{1}\right)^{2}$ went up with the rise in $q_{t}^{1}$ and the fall in the tax rate. The final outcome, shown in the intersection of the dashed lines 
marked 'new' as compared to the 'old' intersection, was that vacancy rates declined.

This analysis implies that the outcome of a lower vacancy rate, i.e., a decline in recruiting activity, took place as the result of the rise in the investment rate, the fall in the tax rate, and the rise in the job filling rate, all of which led to a movement of the marginal costs curve in a counterclockwise direction.

\section{Conclusions}

The paper has provided a consistent picture of firm recruiting behavior in the U.S. First, job values were found to be counter-cyclical, mainly because of labor share cyclicality. The analysis has emphasized their forwardlooking, present value aspect. Second, and as a consequence, hiring from non-employment and the associated job-filling rate are counter-cyclical. This behavior is consistent with known facts in the labor market. These two points are different, though, from the conclusions of the standard search and matching model. Third, the same framework can account for the procyclicality of vacancy rates and job to job flows; these stem from the important interaction of labor recruiting behavior with capital investment behavior. Fourth, both the high volatility of key recruiting variables at business cycle frequency and their declining secular trends can be accounted for, using the same framework. In work in progress (see Faccini and Yashiv $(2015 \mathrm{a}, \mathrm{b}))$ we embed this set-up in a DSGE model and study the effects of technology and monetary policy shocks on recruitment behavior. 


\section{References}

[1] Acemoglu, Daron and William B. Hawkins, 2014."Search with MultiWorker Firms," Theoretical Economics 9,3,583-628.

[2] Alexopoulos, Michelle, 2011. "Read All About It! What Happens Following a Technology Shock," American Economic Review 101, 11441179 .

[3] Alexopoulos, Michelle and Trevor Tombe, 2012. "Management Matters," Journal of Monetary Economics 59, 269-285.

[4] Campbell, John .Y. and Robert J. Shiller, 1988. "The Dividend-Price Ratio and Expectations of Future Dividends and Discount Factors," Review of Financial Studies 1, 195-227.

[5] Christiano, Lawrence. J., Martin S. Eichenbaum, and Mathias Trabandt, 2013. "Unemployment and Business Cycles," NBER Working Paper no. 19265.

[6] Cochrane, John H., 1992. "Explaining the Variance of Price-Dividend Ratios" Review of Financial Studies 5,2,243-280.

[7] Cochrane, John H. 2011. "Discount Rates," Journal of Finance 66, 1047-1108.

[8] Davis, Steven J., R. Jason Faberman, and John C. Haltiwanger, 2006. "The Flow Approach to Labor Markets: New Data Sources and MicroMacro Links," Journal of Economic Perspectives 20,3,3-26.

[9] Davis, Steven J., R. Jason Faberman, and John C. Haltiwanger, 2012. "Labor Market Flows in the Cross Section and Over Time," Journal of Monetary Economics 59, 1, 1-18.

[10] Davis, Steven J., R. Jason Faberman, and John C. Haltiwanger, 2013. "The Establishment-Level Behavior of Vacancies and Hiring," The Quarterly Journal of Economics 128: 581-622.

[11] Davis, Steven J. and John Haltiwanger, 2014. "Labor Market Fluidity and Economic Performance," NBER Working Paper no. 20479.

[12] Faccini, Renato and Eran Yashiv, 2015a. "Frictions in DSGE Models: Revisiting New Keynesian vs New Classical Results," working paper.

[13] Faccini, Renato and Eran Yashiv, 2015b. "Hiring and Investment Frictions as Inflation Determinants," working paper. 
[14] Fallick, Bruce and Fleischman, Charles, 2004. "Employer-to-Employer Flows in the U.S. Labor Market: The Complete Picture of Gross Worker Flows" FEDS \#2004-34.

[15] Gali, Jordi, 2010. "Monetary policy and Unemployment" in Benjamin M. Friedman and Michael Woodford (eds.) Handbook of Monetary Economics Vol. 3A, 487-546, Elsevier, Amsterdam.

[16] Garibaldi, Pietro and Espen R. Moen, 2009. "Industry Dynamics and Search in the Labor Market," working paper.

[17] Gertler, Mark and Antonella Trigari, 2009. "Unemployment Fluctuations with Staggered Nash Wage Bargaining," Journal of Political Economy 117(1), 38-86.

[18] Hagedorn, Marcus and Iourii Manovskii, 2008. "The Cyclical Behavior of Equilibrium Unemployment and Vacancies Revisited," American Economic Review 98(4), 1692-1706.

[19] Hall, Robert E., 2005. "Employment Fluctuations with Equilibrium Wage Stickiness," American Economic Review 95(1), 50-65.

[20] Hall, Robert E., 2014a. "High Discounts and High Unemployment," NBER Working Paper No. 19871.

[21] Hall, Robert E., 2014b. "What the Cyclical Response of Advertising Reveals about Markups and other Macroeconomic Wedges," available at http:/ / web.stanford.edu/ rehall/Ads042314.pdf

[22] Hall, Robert E. and Paul R. Milgrom, 2008. "The Limited Influence of Unemployment on the Wage Bargain," American Economic Review 98(4), 1653-1674.

[23] Hansen, Lars P. 1982. "Large Sample Properties of Generalized Method of Moments Estimators," Econometrica 50:1029-1054.

[24] Hayashi, Fumio 1982. "Tobin's Marginal q and Average q: A Neoclassical Interpretation," Econometrica 50:213-224.

[25] Kahn, Aubhik and Julia K. Thomas, 2008. "Idiosyncratic Shocks and the Role of Nonconvexities in Plant and Aggregate Investment Dynamics," Econometrica 76 (2), 395-436.

[26] Lucas, Robert E. and Edward C. Prescott, 1971. "Investment Under Uncertainty," Econometrica 39, 5, 659-681.

[27] Merz, Monika and Eran Yashiv, 2007. "Labor and the Market Value of the Firm," American Economic Review, 97, 4, 1419-1431. 
[28] Mortensen, Dale T. and Eva Nagypal, 2007. "More on Unemployment and Vacancy Fluctuations," Review of Economic Dynamics, 10(3), 327-347, July.

[29] Nekarda, Christopher J. and Valerie A. Ramey, 2013.“The Cyclical Behavior of the Price-Cost Markup," NBER WP No. 19099.

[30] Nobel Prize, 2013. "Understanding Asset Prices," the Sveriges Riksbank Prize in Economic Sciences 2013.

[31] Pissarides, Christopher A. 2000. Equilibrium Unemployment Theory, 2nd edition, Cambridge, MIT Press.

[32] Rios-Rull, Jose-Victor and Raul Santaeulalia-Llopis, 2010. "Redistributive Shocks and Productivity Shocks,"Journal of Monetary Economics 57, 931-948.

[33] Shimer, Robert ,2005."The cyclical behavior of equilibrium unemployment and vacancies," American Economic Review, 95, 25-49.

[34] Shimer, Robert, 2012. "Reassessing the ins and outs of unemployment." Review of Economic Dynamics 15(2),127-148.

[35] Thomas, Julia K., 2002. "Is Lumpy Investment Relevant for the Busines Cycle?" Journal of Political Economy 110, 3, 508-534.

[36] Tobin, James 1969. “A General Equilibrium Approach to Monetary Theory," Journal of Money, Credit, and Banking 1:15-29.

[37] Yashiv, Eran, 2015. "Capital Values and Job Values," Review of Economic Dynamics, forthcoming. 


\section{Tables and Figures}

Table 1

Alternative Formulations of The Recruiting Equation (1)

\section{Linear Costs Models}

\begin{tabular}{|l|c|c|c|}
\hline & paper & firm size & LHS, costs, arguments \\
\hline \hline 1 & Pissarides (2000, chapter 1) & single job & $v, p$ \\
\hline 2 & Pissarides (2000, chapter 2) & single job & $v$ \\
\hline 3 & Shimer (2005) & single job & $v$ \\
\hline 4 & Hall (2005) & single job & $v$ \\
\hline 5 & Mortensen and Nagypal (2007) & single job & $v$ \\
\hline 6 & Hall and Milgrom (2008) & large & $v$ \\
\hline 7 & Hagedorn and Manovskii (2008) & single job & $v: c^{K} p+c^{w} p^{\xi}$ \\
\hline 8 & Christiano et al (2013) & large & $\frac{h}{n}$ \\
\hline 9 & Hall (2014a) & single job & $v$ \\
\hline
\end{tabular}

\begin{tabular}{|c|c|c|c|c|}
\hline & \multicolumn{4}{|c|}{ RHS, job value } \\
\hline & f (production) & w (wages) & s (separation) & $\rho$ (discounting) \\
\hline \hline 1 & exo, stoch & Nash & exo, constant & constant \\
\hline 2 & exo, stoch & Nash & endo, stoch & constant \\
\hline 3 & exo, stoch & Nash & exo, stoch & constant \\
\hline 4 & exo, stoch & sticky & exo, constant & constant \\
\hline 5 & exo, stoch & Nash / rigid/Calvo & exo, constant & constant \\
\hline 6 & exo, stoch & alternating offers & exo, constant & constant \\
\hline 7 & exo, stoch & Nash & exo, constant & constant \\
\hline 8 & $h_{t}=l_{t} ;$ & alternating offers & exo, constant & GE, IMRS \\
\hline 9 & exo, stoch & Nash/alternating offers & exo, constant & from stock market \\
\hline
\end{tabular}

exo=exogenous

endo=endogenous

stoch $=$ stochastic

$v=$ vacancies, $h=$ hires,$n=$ employment

$\mathrm{GE}=$ General Equilibrium

IMRS=Intertemporal Rate of Substitution 


\section{Convex Costs Models}

\begin{tabular}{|c|c|c|c|c|}
\hline & paper & size & \multicolumn{2}{c|}{ LHS, costs, arguments } \\
\hline & & & arguments & function \\
\hline \hline 1 & Merz and Yashiv (2007) & large & $\frac{h}{n}, \frac{i}{k}, f$ & linear-convex \\
\hline 2 & Gertler and Trigari (2009) & large & $\frac{h}{n}$ & quadratic \\
\hline 3 & Gali (2010) & large & $\frac{h}{u}$ & power \\
\hline 4 & Acemoglu and Hawkins (2014) & large & $v$ & convex \\
\hline
\end{tabular}

\begin{tabular}{|c|c|c|c|c|}
\hline & \multicolumn{4}{|c|}{ RHS, job value } \\
\hline & $\mathbf{f}$ (production) & $\mathbf{w}$ (wages) & s (separation) & $\rho$ (discounting) \\
\hline \hline 1 & $e^{z_{t}} n_{t}^{\alpha} k_{t}^{1-\alpha}$ & exo, stoch & exog, stoch & WACC \\
\hline 2 & $z_{t} n_{t}^{\alpha} k_{t}^{1-\alpha}$ & Nash, Calvo & exo, constant & GE, IMRS \\
\hline 3 & $A_{t} N_{t}^{1-\alpha}$ & Nash, Calvo & exo, constant & GE, IMRS \\
\hline 4 & $y(n ; z)$ & Intrafirm bargaining & exo, constant & constant \\
\hline
\end{tabular}

exo=exogenous

stoch $=$ stochastic

WACC $=$ Weighted Average Cost of Capital 
Table 2

Descriptive Sample Statistics

Quarterly, U.S. data

a. 1976:1-2013:4 $(n=152)$

\begin{tabular}{lccccccccc} 
Variable & $\frac{f}{k}$ & $\tau$ & $\frac{i}{k}$ & $\delta$ & $\frac{w n}{f}$ & $\frac{h^{1}}{n}$ & $\frac{v}{n}$ & $\psi^{1}$ & $\beta$ \\
\hline \hline Mean & 0.14 & 0.38 & 0.024 & 0.02 & 0.62 & 0.126 & 0.031 & 0.125 & 0.99 \\
Standard Deviation & 0.01 & 0.05 & 0.003 & 0.003 & 0.02 & 0.010 & 0.007 & 0.010 & 0.005
\end{tabular}

b. 1994:1-2013:4 $(n=80)$

\begin{tabular}{|c|c|c|c|c|c|c|c|c|}
\hline Variable & $\frac{f}{k}$ & $\tau$ & $\frac{i}{k}$ & $\delta$ & $\frac{w n}{f}$ & $\frac{h}{n}=\frac{h^{1}+h^{2}}{n}$ & $\frac{v}{n}$ & $\psi=\psi^{1}+\psi^{2}$ \\
\hline Mean & 0.15 & 0.34 & $\overline{0.026}$ & 0.02 & $\overline{0.61}$ & 0.178 & 0.028 & 0.178 \\
\hline \multirow[t]{3}{*}{ Standard Deviation } & 0.01 & 0.005 & 0.002 & 0.002 & 0.03 & 0.012 & 0.005 & 0.012 \\
\hline & & & & $\beta$ & & & & \\
\hline & $\begin{array}{l}\text { Mear } \\
\text { Stan }\end{array}$ & d De & ation & $\begin{array}{c}0.99 \\
0.005\end{array}$ & & & & \\
\hline
\end{tabular}


Table 3

Co-Movement of Hiring Rates from Non Employment and GDP

$$
\begin{array}{cccccccc}
\multicolumn{8}{c}{\rho\left(\frac{h_{t}^{1}}{n_{t}}, f_{t+i}\right)} \\
i & -8 & -4 & -1 & 0 & 1 & 4 & 8 \\
\hline \hline-0.15 & -0.35 & -0.39 & -0.30 & -0.15 & 0.11 & 0.23
\end{array}
$$

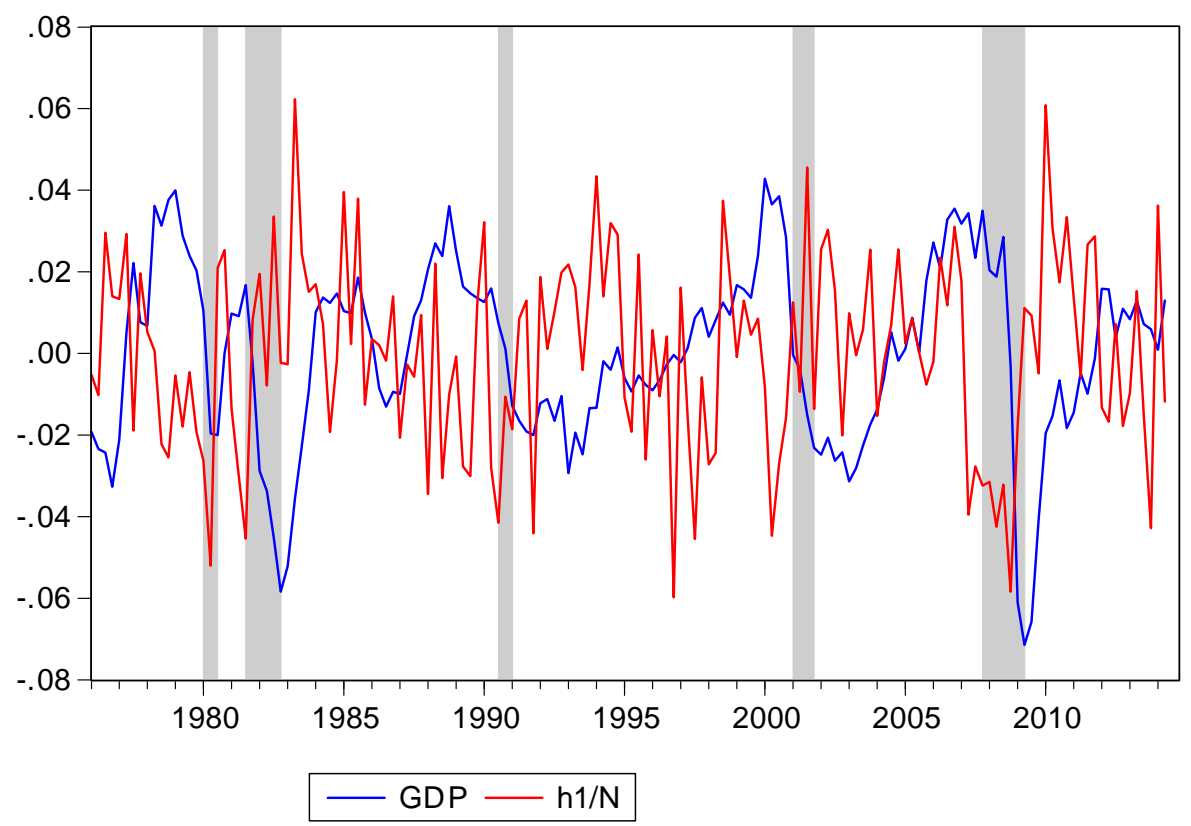

Figure 1: Cyclicality of $\frac{h_{t}^{1}}{n_{t}}$ 
Table 4

Co-Movement of Hiring Rates from Employment (job to job flows) and GDP

$$
\begin{array}{cccccccc}
\multicolumn{8}{c}{\rho\left(\frac{h_{t}^{2}}{h_{t}}, f_{t+i}\right)} \\
i & -8 & -4 & -1 & 0 & 1 & 4 & 8 \\
\hline \hline-0.13 & 0.26 & 0.64 & 0.68 & 0.66 & 0.28 & -0.05
\end{array}
$$

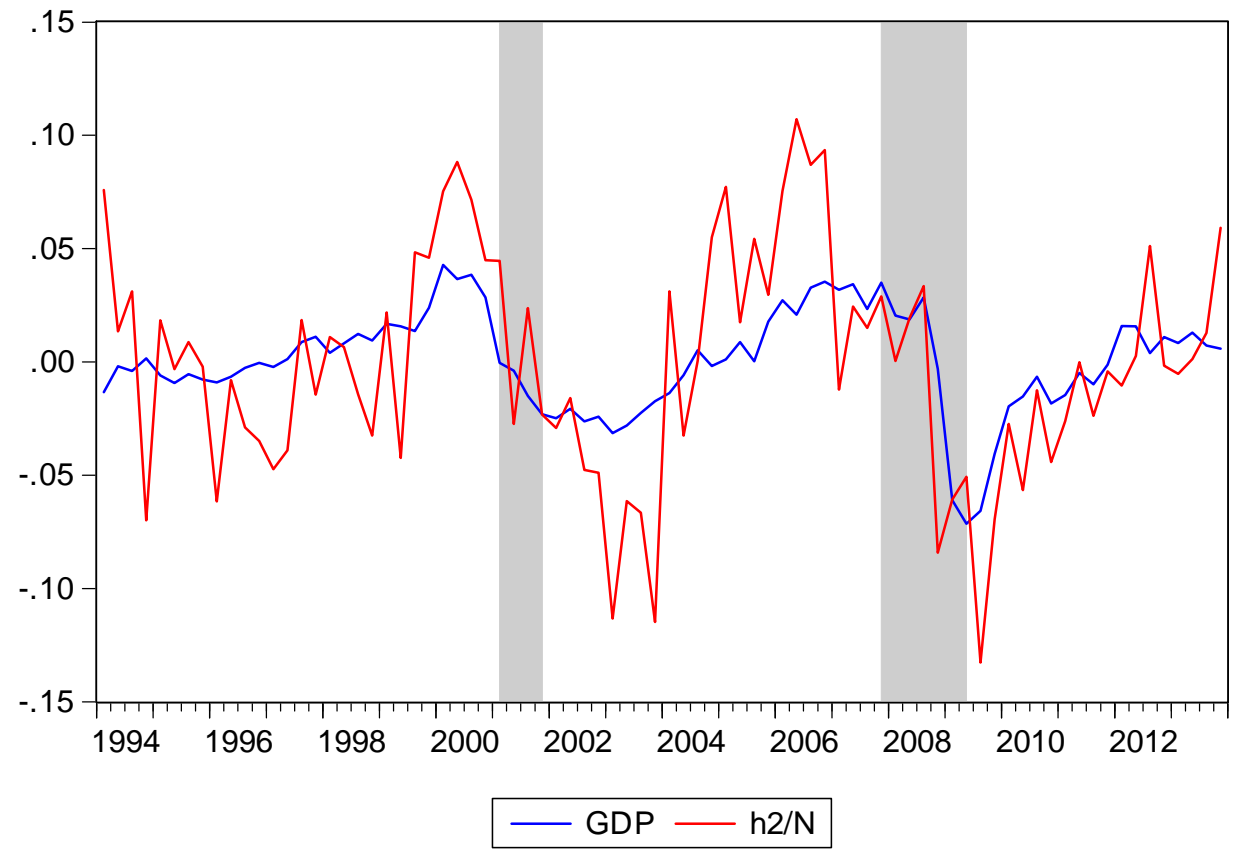

Figure 2: Cyclicality of $\frac{h_{t}^{2}}{n_{t}}$ 
Table 5

Co-Movement of Vacancy Rates and GDP

$$
\begin{array}{cccccccc}
\multicolumn{8}{c}{\rho\left(\frac{v_{t}}{n_{t}}, f_{t+i}\right)} \\
i & -8 & -4 & -1 & 0 & 1 & 4 & 8 \\
\hline \hline-0.26 & 0.29 & 0.82 & 0.89 & 0.83 & 0.39 & -0.13
\end{array}
$$

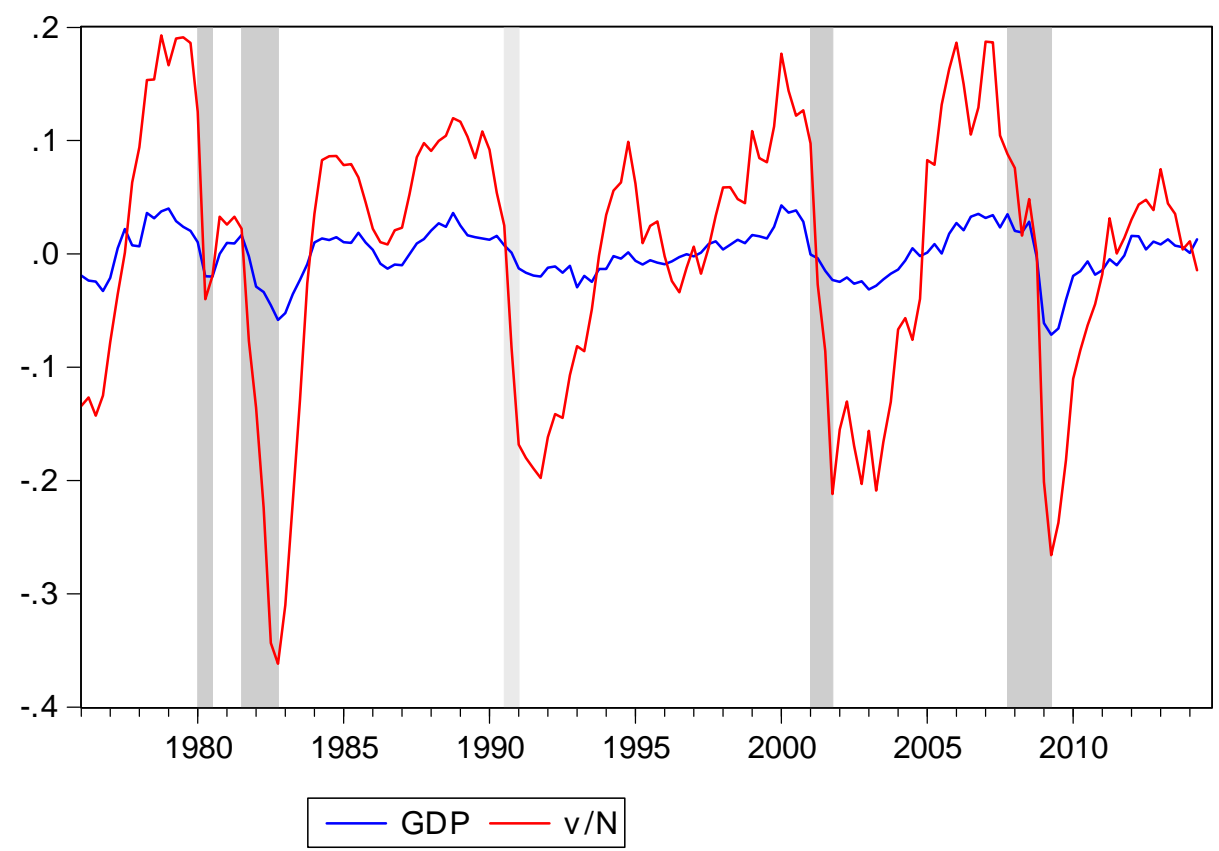

Figure 3: Cyclicality of $\frac{v_{t}}{n_{t}}$ 
Table 6

Total Hiring Flows (NSA, 000s)

Sample: $2001: 1-2014: 06$

\begin{tabular}{l|cc} 
& CPS & JOLTS \\
\hline \hline Mean & 8595 & 4698 \\
Median & 8609 & 4765 \\
Std. Dev. & 496 & 484 \\
C.O.V & 0.06 & 0.10 \\
Skewness & 0.25 & -0.25 \\
Kurtosis & 2.42 & 2.14
\end{tabular}

Table 7

Stochastic Behavior of the Gross Hiring Rate and Other Labor Market Variables

Co-Movement (contemporaneous correlation) with GDP

$$
\begin{aligned}
& \text { logged, HP filtered } \\
& \begin{array}{cccc}
\frac{h_{t}^{1}}{n_{t}} & \frac{h_{t}^{1}}{u_{t}+o_{t}} & \frac{u_{t}+o_{t}}{p o p_{t}} & \frac{\frac{1}{n_{t}}}{p o p_{t}} \\
\hline \hline-0.25 & 0.53 & -0.72 & -0.82
\end{array}
\end{aligned}
$$



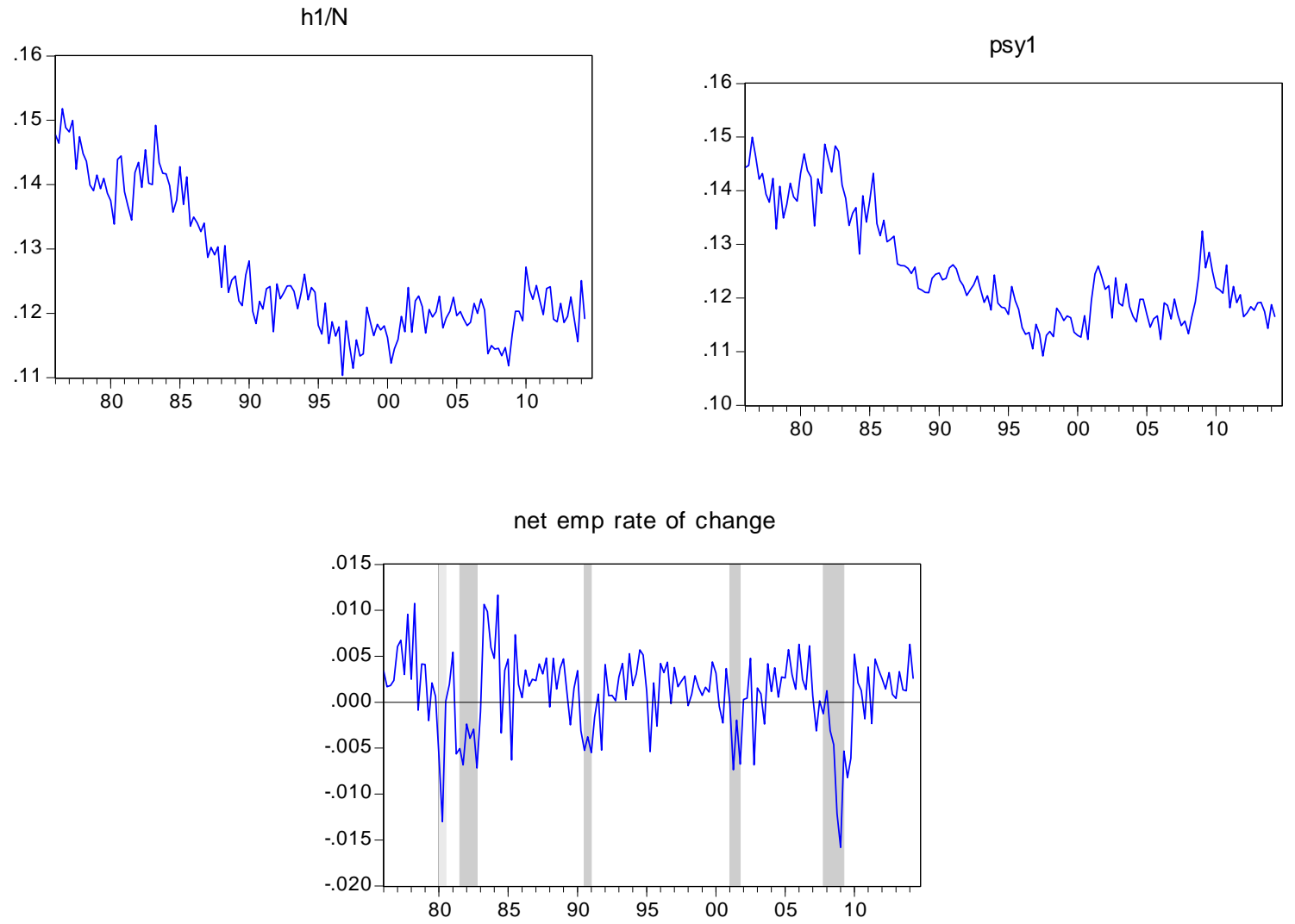

Figure 4: Gross and Net Flows $\frac{h_{t}^{1}}{n_{t}}, \psi_{t}^{1}, \frac{n_{t+1}-n_{t}}{n_{t}}$ 


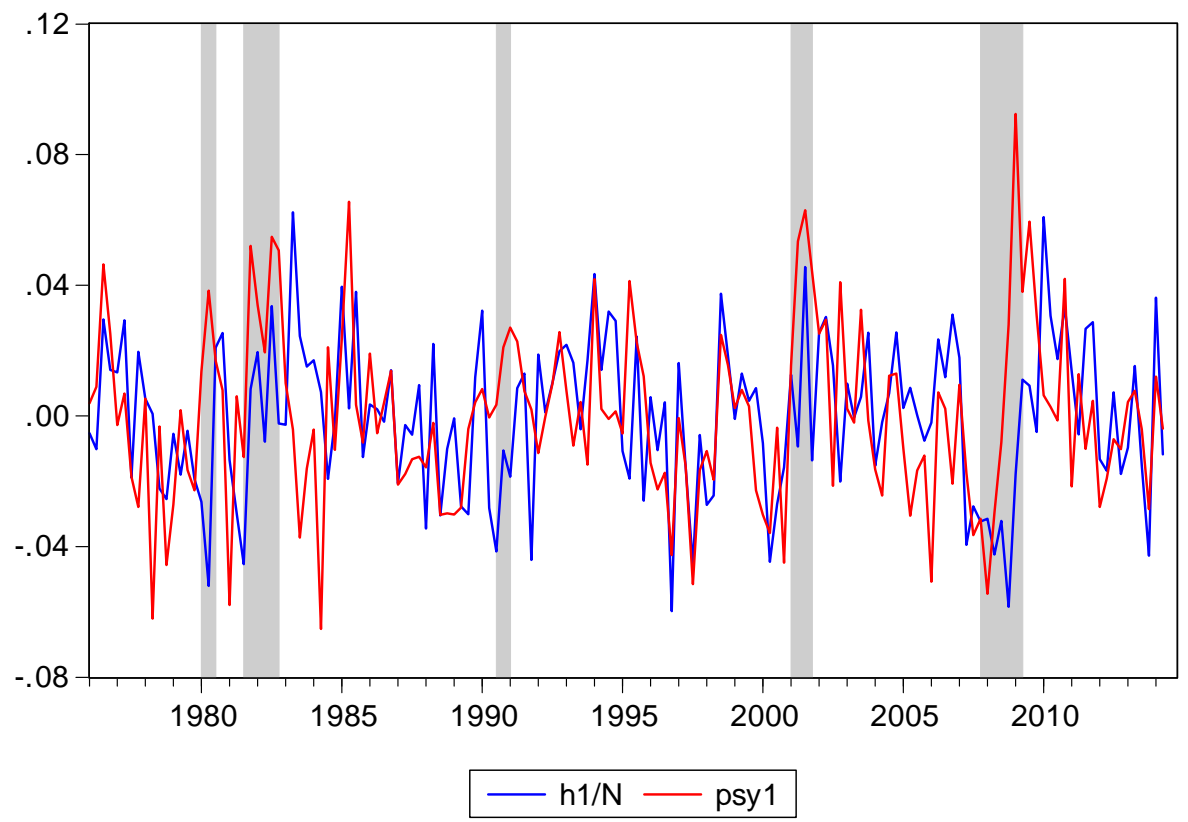

Figure 5: $\frac{h_{t}^{1}}{n_{t}}, \psi_{t}$ logged, HP filtered 
Table 8

GMM Estimates

\begin{tabular}{|c|c|c|c|c|c|c|c|}
\hline & specification & $e_{1}$ & $e_{2}$ & $e_{31}$ & $e_{32}$ & $\alpha$ & J-Statistic \\
\hline$a$ & benchmark & $\begin{array}{l}77.3 \\
(6.3)\end{array}$ & $\begin{array}{c}9.1 \\
(1.0)\end{array}$ & $\begin{array}{l}-2.8 \\
(1.2)\end{array}$ & $\begin{array}{l}-19.6 \\
(0.9)\end{array}$ & $\begin{array}{c}0.66 \\
(0.003)\end{array}$ & $\begin{array}{c}51.6 \\
(0.74)\end{array}$ \\
\hline$b$ & $\begin{array}{c}\text { constrained case } \\
\lambda_{1}=0.9 ; \lambda_{2}=0 \\
1976-2013\end{array}$ & $\begin{array}{l}32.2 \\
(6.4)\end{array}$ & $\begin{array}{c}2.3 \\
(0.4)\end{array}$ & $\begin{array}{l}-1.5 \\
(0.9)\end{array}$ & - & $\begin{array}{c}0.65 \\
-\end{array}$ & $\begin{array}{c}83.9 \\
(0.30)\end{array}$ \\
\hline C & Tobin's q for $N$ & $\begin{array}{l}0 \\
-\end{array}$ & $\begin{array}{l}30.8 \\
(0.9)\end{array}$ & $\begin{array}{l}0 \\
-\end{array}$ & $\begin{array}{l}0 \\
-\end{array}$ & $\begin{array}{c}0.70 \\
(0.003)\end{array}$ & $\begin{array}{c}61.9 \\
(0.48)\end{array}$ \\
\hline$d$ & $\begin{array}{l}\text { Standard matching model } \\
\qquad \eta_{2}=1, \lambda_{1}=\lambda_{2}=0\end{array}$ & $\begin{array}{l}0 \\
-\end{array}$ & $\begin{array}{l}9.3 \\
(0.1)\end{array}$ & $\begin{array}{l}0 \\
-\end{array}$ & $\begin{array}{l}0 \\
-\end{array}$ & $\begin{array}{c}0.77 \\
(0.002)\end{array}$ & $\begin{array}{c}62.5 \\
(0.46)\end{array}$ \\
\hline
\end{tabular}

\section{Notes:}

1. The tables report point estimates with standard errors in parentheses. The J-statistic is reported with $p$ value in parentheses.

2. The following parameter values are set unless indicated otherwise: $\lambda_{1}=0.6 ; \lambda_{2}=0.2 ; \eta_{1}=\eta_{2}=2, \eta_{31}=\eta_{32}=1$.

3. The sample period is 1994:1 - 2013:4, except for Row b where it is 1976:1-2013:4. 
Table 9

Estimated Marginal Costs - Data Moments

$1994: 1-2013: 4$

\section{benchmark constrained Tobin's $Q$ for $N$ Std matching model}

\begin{tabular}{lllll}
\hline \hline & & & & \\
mean & 0.12 & 0.13 & 0.90 & 0.97 \\
median & 0.12 & 0.13 & 0.89 & 1.00 \\
std. & 0.03 & 0.01 & 0.03 & 0.13 \\
auto-correlation & 0.91 & 0.80 & 0.55 & 0.92
\end{tabular}

\section{Notes:}

1. The series in the table are the LHS of the estimated equation (reported in Table 8) namely $\left(1-\tau_{t}\right) \frac{g_{v_{t}}}{q_{t} \frac{f_{t}}{n_{t}}}$.

2. The sample period is 1994:1-2013:4, except for column "constrained" where it is 1976:1-2013:4. 
Table 10

Variance Decomposition $(T=30)$

\begin{tabular}{|c|c|c|c|c|}
\hline & 1 & 2 & 3 & 4 \\
\hline & benchmark & constrained & Tobin's q & Std model \\
\hline $\operatorname{var}\left(P V_{t, T}\right)$ & 0.01 & 0.01 & 0.01 & 0.01 \\
\hline$\frac{\frac{\Omega^{r} \Omega f_{E(M P)}}{1-\Omega} \sum_{j=1}^{T}(\Omega)^{j-1} \operatorname{cov}\left(P_{t}, g_{t+j}^{r}\right)}{\operatorname{var}\left(P V_{t, T}\right)}$ & 0.04 & 0.01 & 0.09 & 0.07 \\
\hline$\frac{\frac{\Omega^{r} \Omega^{f} E(M P)}{1-\Omega} \sum_{j=1}^{T}(\Omega)^{j-1} \operatorname{cov}\left(P_{t}, g_{t+j}^{f}\right)}{\operatorname{var}\left(P V_{t, T}\right)}$ & -0.02 & -0.001 & 0.04 & 0.03 \\
\hline$\frac{\frac{\Omega^{r} \Omega f_{E(M P)}}{1-\Omega} \sum_{j=2}^{T}(\Omega)^{j-1} \operatorname{cov}\left(P_{t}, g_{t+j}^{s}\right)}{\operatorname{var}\left(P V_{t, T}\right)}$ & -0.007 & 0.07 & 0.06 & 0.06 \\
\hline$\frac{\Omega^{r} \Omega^{f} \sum_{j=1}^{T}(\Omega)^{j-1} \operatorname{cov}\left(P_{t}, M P_{t+j}\right)}{\operatorname{var}\left(P V_{t, T}\right)}$ & 0.74 & 0.60 & 0.78 & 0.62 \\
\hline residual & 0.24 & 0.32 & 0.02 & 0.21 \\
\hline
\end{tabular}

Notes:

1. See Appendix E. The basic decomposition equation is:

$$
\begin{aligned}
\operatorname{var}\left(P V_{t}\right) \cong & \frac{\Omega^{r} \Omega^{f} E(M P)}{1-\Omega} \sum_{j=1}^{T}(\Omega)^{j-1} \operatorname{cov}\left(P V_{t}, g_{t+j}^{r}\right)+ \\
& \frac{\Omega^{r} \Omega^{f} E(M P)}{1-\Omega} \sum_{j=1}^{T}(\Omega)^{j-1} \operatorname{cov}\left(P V_{t}, g_{t+j}^{f}\right)+ \\
& \frac{\Omega^{r} \Omega^{f} E(M P)}{1-\Omega} \sum_{j=2}^{T}(\Omega)^{j-1} \operatorname{cov}\left(P V_{t}, g_{t+j}^{s}\right)+ \\
& \Omega^{r} \Omega^{f} \sum_{j=1}^{T}(\Omega)^{j-1} \operatorname{cov}\left(P V_{t}, M P_{t+j}\right)
\end{aligned}
$$




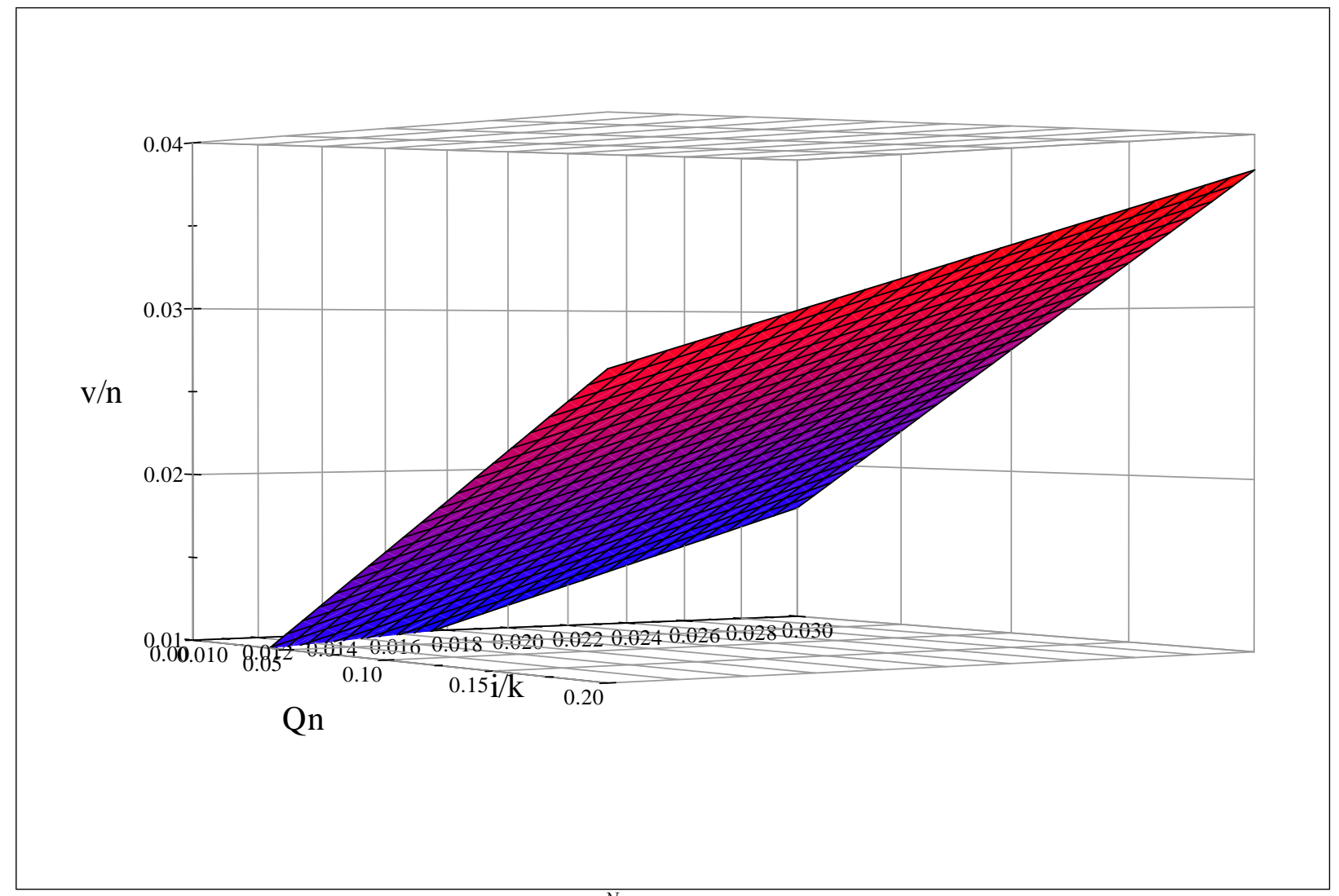

Figure 6: Recruitment $\left(\frac{v_{t}}{n_{t}}\right)$, Job Values $\left(\frac{Q_{t}^{N}}{\frac{f_{t}}{n_{t}}}\right)$, and Investment Rates $\left(\frac{i_{t}}{k_{t}}\right)$ 


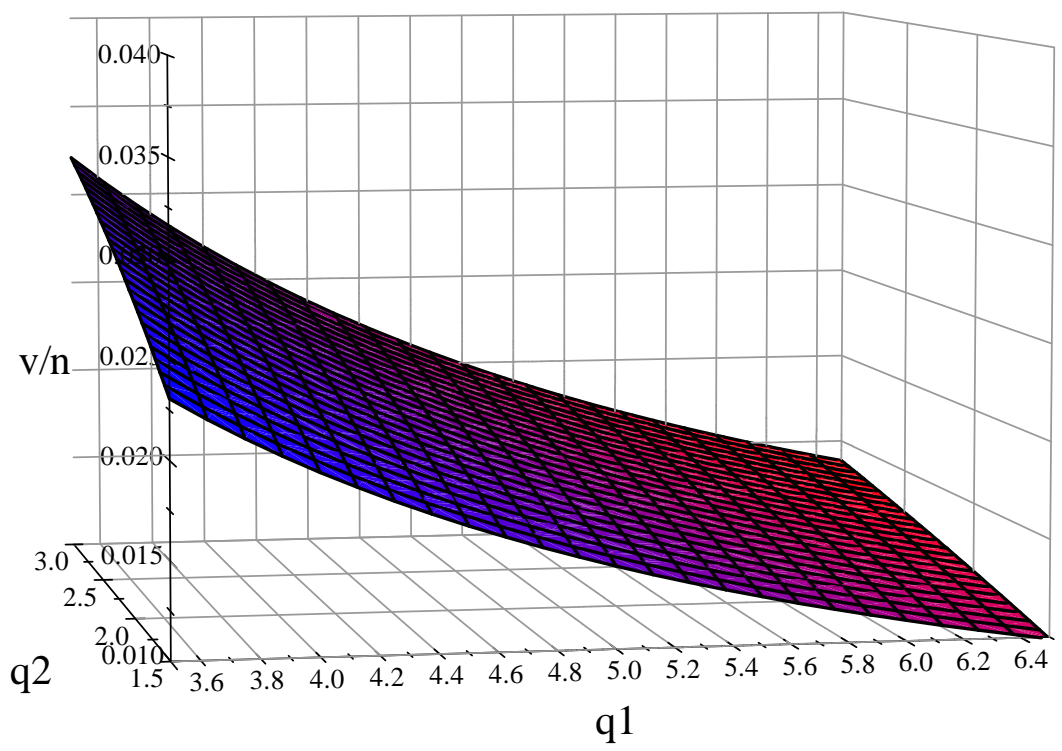

Figure 7: Recruitment $\left(\frac{v_{t}}{n_{t}}\right)$ and Job Filling Rates $\left(q_{t}^{1}, q_{t}^{2}\right)$ 


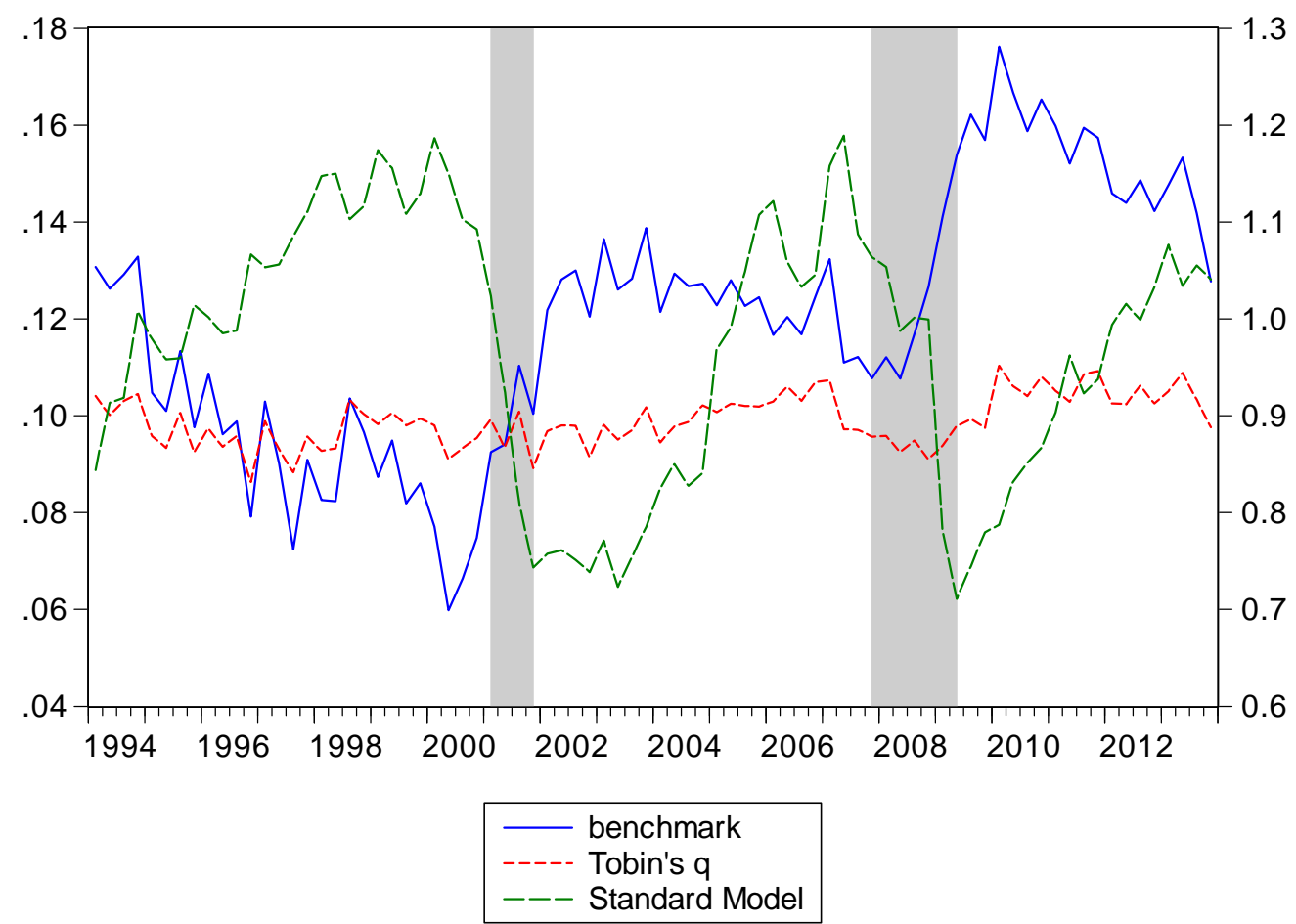

Figure 8: Job Values Across Models

\section{Notes:}

1. Benchmark refers to the preferred specification of Table 8, row (a). Its values are given on the LHS.

2. Tobin's q and standard model refer to the specifications of Table 8, rows (c) and (d), respectively. Their values are given on the RHS.

3. NBER-dated recessions are shaded. 
Table 11

Job Value Cyclicality

$\rho\left(L H S_{t}, f_{t+i}\right)$

HP filtered $(\lambda=1600)$

Benchmark Model

\begin{tabular}{cccccccc}
$i$ & -8 & -4 & -1 & 0 & 1 & 4 & 8 \\
\hline \hline$y$ & -0.04 & -0.46 & -0.67 & -0.63 & -0.49 & 0.04 & 0.33
\end{tabular}

Constrained Case

\begin{tabular}{cccccccc}
$i$ & -8 & -4 & -1 & 0 & 1 & 4 & 8 \\
\hline \hline$y$ & 0.04 & -0.29 & -0.38 & -0.29 & -0.14 & 0.21 & 0.32
\end{tabular}

Tobin's q

\begin{tabular}{cccccccc}
$i$ & -8 & -4 & -1 & 0 & 1 & 4 & 8 \\
\hline \hline$y$ & -0.28 & -0.24 & 0.03 & 0.13 & 0.27 & 0.41 & 0.19
\end{tabular}

Standard Model

\begin{tabular}{cccccccc}
$i$ & -8 & -4 & -1 & 0 & 1 & 4 & 8 \\
\hline \hline$y$ & -0.26 & 0.38 & 0.85 & 0.90 & 0.79 & 0.39 & -0.18
\end{tabular}


Table 12a

Volatility of Recruiting Variables

\begin{tabular}{|c|c|}
\hline & std \\
\hline$\frac{i_{t}}{k_{t}}$ & 0.07 \\
\hline$q_{t}^{1}$ & 0.12 \\
\hline$q_{t}^{2}$ & 0.08 \\
\hline$\frac{v_{t}}{n_{t}}$ & 0.11 \\
\hline$\frac{h_{t}}{n_{t}}$ & 0.02 \\
\hline$\frac{h_{t}^{1}}{n_{t}}$ & 0.02 \\
\hline
\end{tabular}

Table 12b

Moments of the Determinants of Recruitment

\begin{tabular}{|l|l|l|}
\hline & $f_{t}$ & $\frac{Q_{t}^{N}}{\left(1-\tau_{t}\right) \frac{f_{t}}{n_{t}}}$ \\
\hline std & 0.02 & 0.12 \\
\hline$\rho$ & & -0.63 \\
\hline
\end{tabular}

Table 12c

Co-Movement of Recruiting Variables

\begin{tabular}{|l|c|c|}
\hline$\rho$ (row,column $)$ & $f_{t}$ & $\frac{Q_{t}^{N}}{\left(1-\tau_{t}\right) \frac{f_{t}}{n_{t}}}$ \\
\hline$\frac{i_{t}}{k_{t}}$ & 0.87 & -0.83 \\
\hline$q_{t}^{1}$ & -0.89 & 0.67 \\
\hline$q_{t}^{2}$ & -0.79 & 0.39 \\
\hline$\frac{v_{t}}{n_{t}}$ & 0.91 & -0.56 \\
\hline$\frac{h_{t}}{n_{t}}$ & 0.27 & 0.15 \\
\hline$\frac{h_{t}^{1}}{n_{t}}$ & -0.28 & 0.78 \\
\hline
\end{tabular}

Notes:

1. All series are logged and HP-filtered.

2. $Q_{t}^{N}$ is computed using the point estimates of row (a) in Table 8 . 

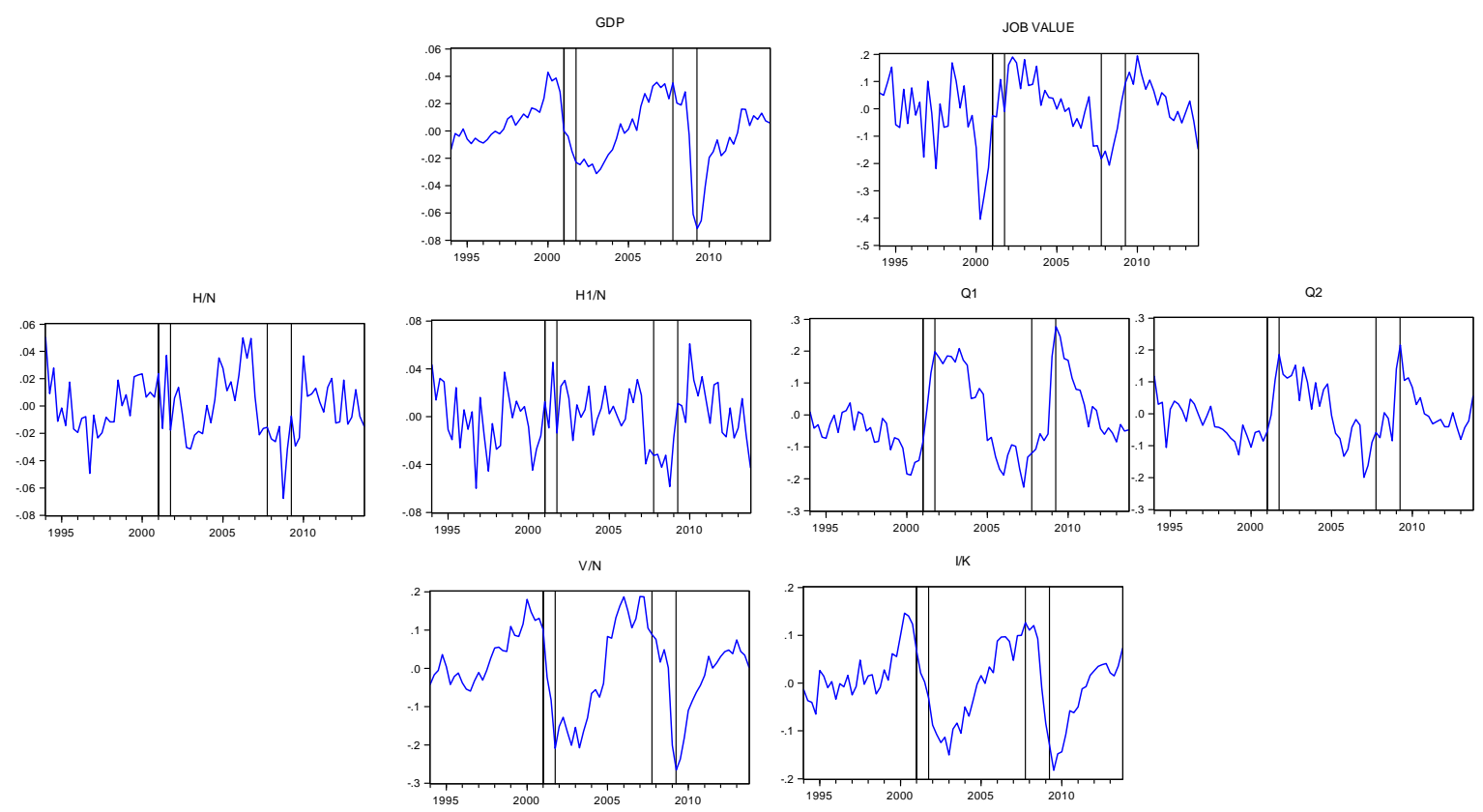

Figure 9: Logged, HP filtered Series

Notes:

NBER-dated recessions are shown betwen the vertical lines. 
Table 13

Variance Decomposition: The Vacancy Rate

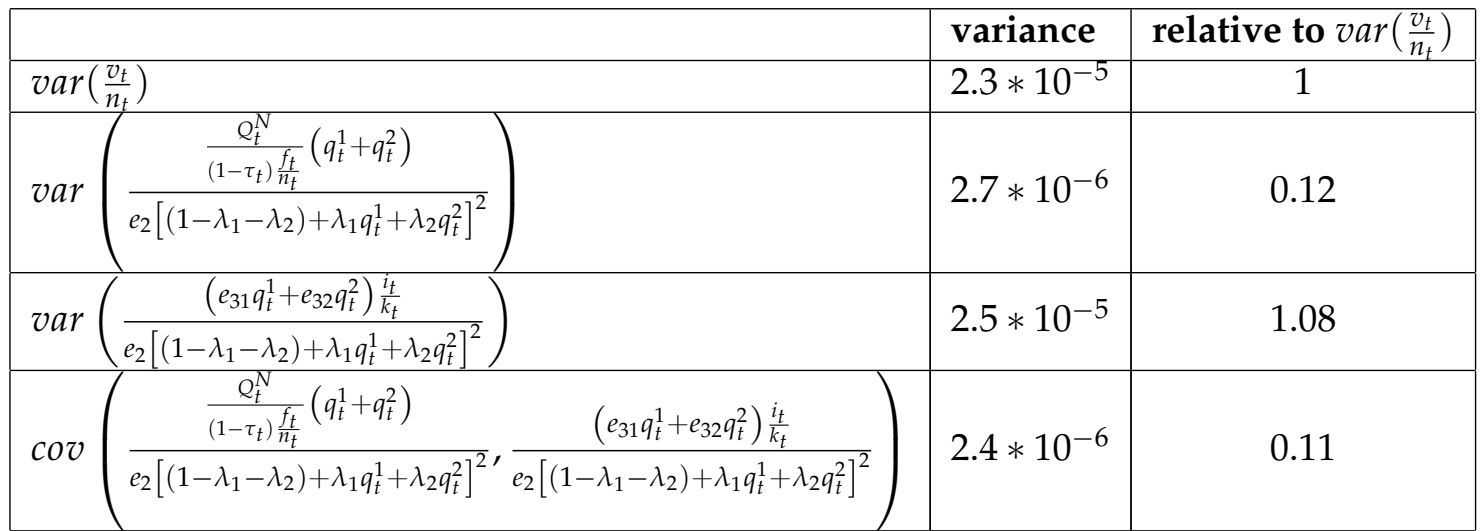

Table 14

Co-Movement: The Vacancy Rate

\begin{tabular}{|c|c|c|}
\hline & $\left(\frac{v_{t}}{n_{t}}, f_{t}\right)$ & 0.91 \\
\hline$\rho$ & $\frac{\frac{Q_{t}^{N}}{\left(1-\tau_{t}\right) \frac{f_{t}}{n_{t}}}\left(q_{t}^{1}+q_{t}^{2}\right)}{e_{2}\left[\left(1-\lambda_{1}-\lambda_{2}\right)+\lambda_{1} q_{t}^{1}+\lambda_{2} q_{t}^{2}\right)^{2}}, f_{t}$ & 0.26 \\
\hline$\rho$ & $\left(\frac{-\left(e_{31} q_{t}^{1}+e_{32} q_{t}^{2}\right) \frac{i_{t}}{k_{t}}}{e_{2}\left[\left(1-\lambda_{1}-\lambda_{2}\right)+\lambda_{1} q_{t}^{1}+\lambda_{2} q_{t}^{2}\right]^{2}}, f_{t}\right.$ & 0.92 \\
\hline
\end{tabular}

\begin{tabular}{|l|c|}
\hline$\rho\left(\frac{v_{t}}{n_{t}}, \frac{Q_{t}^{N}}{\left(1-\tau_{t}\right) \frac{f_{t}}{n_{t}}}\right)$ & -0.56 \\
\hline$\rho\left(\frac{\frac{Q_{t}^{N}}{\left(1-\tau_{t}\right) \frac{f_{t}}{n_{t}}}\left(q_{t}^{1}+q_{t}^{2}\right)}{e_{2}\left[\left(1-\lambda_{1}-\lambda_{2}\right)+\lambda_{1} q_{t}^{1}+\lambda_{2} q_{t}^{2}\right]^{2}}, \frac{Q_{t}^{N}}{\left(1-\tau_{t}\right) \frac{f_{t}}{n_{t}}}\right)$ & 0.49 \\
\hline$\rho\left(\frac{-\left(e_{31} q_{t}^{1}+e_{32} q_{t}^{2}\right) \frac{i_{t}}{k_{t}}}{e_{2}\left[\left(1-\lambda_{1}-\lambda_{2}\right)+\lambda_{1} q_{t}^{1}+\lambda_{2} q_{t}^{2}\right]^{2}}, \frac{Q_{t}^{N}}{\left(1-\tau_{t}\right) \frac{f_{t}}{n_{t}}}\right)$ & -0.77 \\
\hline
\end{tabular}

Notes:

1. All series are logged and HP-filtered.

2. $Q_{t}^{N}$ is computed using the point estimates of row (a) in Table 8 . 
Table 15

Variance Decomposition: The Total Hiring Rate

\begin{tabular}{|l|l|c|}
\hline $\operatorname{var}\left(\frac{h_{t}}{n_{t}}\right)$ & variance & relative to $\operatorname{var}\left(\frac{h_{t}}{n_{t}}\right)$ \\
\hline $\operatorname{var}\left(\frac{\frac{Q_{t}^{N}}{\left(1-\tau_{t} \frac{f_{t}}{n_{t}}\right.}\left(q_{t}^{1}+q_{t}^{2}\right)^{2}}{e_{2}\left[\left(1-\lambda_{1}-\lambda_{2}\right)+\lambda_{1} q_{t}^{1}+\lambda_{2} q_{t}^{2}\right]^{2}}\right)$ & $1.5 * 10^{-4}$ & 1 \\
\hline $\operatorname{var}\left(\frac{\left(q_{t}^{1}+q_{t}^{2}\right)\left(e_{31} q_{t}^{1}+e_{32} q_{t}^{2}\right) \frac{i_{t}}{k_{t}}}{e_{2}\left[\left(1-\lambda_{1}-\lambda_{2}\right)+\lambda_{1} q_{t}^{1}+\lambda_{2} q_{t}^{2}\right]^{2}}\right)$ & $1.8 * 10^{-4}$ & 1.19 \\
\hline $\operatorname{cov}\left(\begin{array}{c}\frac{Q_{t}^{N}}{\left(1-\tau_{t} \frac{f_{t}}{n_{t}}\right.}\left(q_{t}^{1}+q_{t}^{2}\right)^{2} \\
\frac{e_{2}\left[\left(1-\lambda_{1}-\lambda_{2}\right)+\lambda_{1} q_{t}^{1}+\lambda_{2} q_{t}^{2}\right]^{2}}{\left(q_{t}^{1}+q_{t}^{2}\right)\left(e_{31} q_{t}^{1}+e_{32} q_{t}^{2}\right) \frac{t_{t}}{k_{t}}} \\
\frac{e_{2}\left[\left(1-\lambda_{1}-\lambda_{2}\right)+\lambda_{1} q_{t}^{1}+\lambda_{2} q_{t}^{2}\right]^{2}}{2}\end{array}\right)$ & $2.3 * 10^{-4}$ & 2.90 \\
\hline
\end{tabular}

Table 16

Co-Movement: The Total Hiring Rate

\begin{tabular}{|l|c|}
\hline$\rho\left(\frac{h_{t}}{n_{t}}, f_{t}\right)$ & 0.27 \\
\hline$\rho\left(\frac{\frac{Q_{t}^{N}}{\left(1-\tau_{t}\right) \frac{f_{t}}{n_{t}}}\left(q_{t}^{1}+q_{t}^{2}\right)^{2}}{e_{2}\left[\left(1-\lambda_{1}-\lambda_{2}\right)+\lambda_{1} q_{t}^{1}+\lambda_{2} q_{t}^{2}\right]^{2}}, f_{t}\right)$ & -0.65 \\
\hline$\rho\left(\frac{-\left(q_{t}^{1}+q_{t}^{2}\right)\left(e_{31} q_{t}^{1}+e_{32} q_{t}^{2}\right) \frac{i_{t}}{k_{t}}}{e_{2}\left[\left(1-\lambda_{1}-\lambda_{2}\right)+\lambda_{1} q_{t}^{1}+\lambda_{2} q_{t}^{2}\right]^{2}}, f_{t}\right)$ & 0.82 \\
\hline
\end{tabular}

\begin{tabular}{|l|c|}
\hline$\rho\left(\frac{h_{t}}{n_{t}}, \frac{Q_{t}^{N}}{\left(1-\tau_{t}\right) \frac{f_{t}}{n_{t}}}\right)$ & 0.15 \\
\hline$\rho\left(\frac{\frac{Q_{t}^{N}}{\left(1-\tau_{t}\right) \frac{f_{t}}{n_{t}}}\left(q_{t}^{1}+q_{t}^{2}\right)^{2}}{e_{2}\left[\left(1-\lambda_{1}-\lambda_{2}\right)+\lambda_{1} q_{t}^{1}+\lambda_{2} q_{t}^{2}\right]^{2}}, \frac{Q_{t}^{N}}{\left(1-\tau_{t}\right) \frac{f_{t}}{n_{t}}}\right)$ & 0.99 \\
\hline$\rho\left(\frac{-\left(q_{t}^{1}+q_{t}^{2}\right)\left(e_{31} q_{t}^{1}+e_{32} q_{t}^{2}\right) \frac{i_{t}}{k_{t}}}{e_{2}\left[\left(1-\lambda_{1}-\lambda_{2}\right)+\lambda_{1} q_{t}^{1}+\lambda_{2} q_{t}^{2}\right]^{2}}, \frac{Q_{t}^{N}}{\left(1-\tau_{t}\right) \frac{f_{t}}{n_{t}}}\right)$ & -0.86 \\
\hline
\end{tabular}

Notes:

1. All series are logged and HP-filtered.

2. $Q_{t}^{N}$ is computed using the point estimates of row (a) in Table 8 . 
Table 17

Variance Decomposition: The Hiring Rate (from non-employment)

\begin{tabular}{|l|l|c|}
\hline $\operatorname{var}\left(\frac{h_{t}^{1}}{n_{t}}\right)$ & variance & relative to $\operatorname{var}\left(\frac{h_{t}^{1}}{n_{t}}\right)$ \\
\hline $\operatorname{var}\left(\frac{\frac{Q_{t}^{N}}{\left(1-\tau_{t}\right) \frac{f_{t}}{n_{t}}\left(q_{t}^{1}+q_{t}^{2}\right) q_{t}^{1}}}{e_{2}\left[\left(1-\lambda_{1}-\lambda_{2}\right)+\lambda_{1} q_{t}^{1}+\lambda_{2} q_{t}^{2}\right]^{2}}\right)$ & $1.2 * 10^{-5}$ & 1 \\
\hline $\operatorname{var}\left(\frac{q_{t}^{1}\left(e_{31} q_{t}^{1}+e_{32} q_{t}^{2}\right) \frac{i_{t}}{k_{t}}}{e_{2}\left[\left(1-\lambda_{1}-\lambda_{2}\right)+\lambda_{1} q_{t}^{1}+\lambda_{2} q_{t}^{2}\right]^{2}}\right)$ & $1.4 * 10^{-4}$ & 11.4 \\
\hline $\operatorname{cov}\left(\frac{\frac{Q_{t}^{N}}{\left(1-\tau_{t}\right) \frac{f_{t}}{n_{t}}\left(q_{t}^{1}+q_{t}^{2}\right) q_{t}^{1}}}{e_{2}\left[\left(1-\lambda_{1}-\lambda_{2}\right)+\lambda_{1} q_{t}^{1}+\lambda_{2} q_{t}^{2}\right]^{2}}, \frac{q_{t}^{1}\left(e_{31} q_{t}^{1}+e_{32} q_{t}^{2}\right) \frac{i_{t}}{k_{t}}}{e_{2}\left[\left(1-\lambda_{1}-\lambda_{2}\right)+\lambda_{1} q_{t}^{1}+\lambda_{2} q_{t}^{2}\right]^{2}}\right)$ & $1.1 * 10^{-4}$ & 9.6 \\
\hline
\end{tabular}

Table 18

Co-Movement: The Hiring Rate (from non-employment)

\begin{tabular}{|c|c|c|}
\hline & $\left.\frac{h_{t}^{1}}{n_{t}}, f_{t}\right)$ & -0.28 \\
\hline$\rho$ & $\frac{\frac{Q_{t}^{N}}{\left(1-\tau_{t}\right) \frac{f_{t}}{n_{t}}}\left(q_{t}^{1}+q_{t}^{2}\right) q_{t}^{1}}{e_{2}\left[\left(1-\lambda_{1}-\lambda_{2}\right)+\lambda_{1} q_{t}^{1}+\lambda_{2} q_{t}^{2}\right]^{2}}, f_{t}$ & -0.68 \\
\hline$\rho$ & $\frac{-q_{t}^{1}\left(e_{31} q_{t}^{1}+e_{32} q_{t}^{2}\right) \frac{i_{t}}{k_{t}}}{e_{2}\left[\left(1-\lambda_{1}-\lambda_{2}\right)+\lambda_{1} q_{t}^{1}+\lambda_{2} q_{t}^{2}\right]^{2}}, f_{t}$ & 0.84 \\
\hline
\end{tabular}

\begin{tabular}{|l|l|}
\hline$\rho\left(\frac{h_{t}^{1}}{n_{t}}, \frac{Q_{t}^{N}}{\left(1-\tau_{t}\right) \frac{f_{t}}{n_{t}}}\right)$ & 0.78 \\
\hline$\rho\left(\frac{\frac{Q_{t}^{N}}{\left(1-\tau_{t}\right) \frac{f_{t}}{n_{t}}}\left(q_{t}^{1}+q_{t}^{2}\right) q_{t}^{1}}{e_{2}\left[\left(1-\lambda_{1}-\lambda_{2}\right)+\lambda_{1} q_{t}^{1}+\lambda_{2} q_{t}^{2}\right]^{2}}, \frac{Q_{t}^{N}}{\left(1-\tau_{t}\right) \frac{f_{t}}{n_{t}}}\right)$ & 0.997 \\
\hline$\rho\left(\frac{-q_{t}^{1}\left(e_{31} q_{t}^{1}+e_{32} q_{t}^{2}\right) \frac{i_{t}}{k_{t}}}{e_{2}\left[\left(1-\lambda_{1}-\lambda_{2}\right)+\lambda_{1} q_{t}^{1}+\lambda_{2} q_{t}^{2}\right]^{2}}, \frac{Q_{t}^{N}}{\left(1-\tau_{t}\right) \frac{f_{t}}{n_{t}}}\right)$ & -0.84 \\
\hline
\end{tabular}

Notes:

1. All series are logged and HP-filtered.

2. $Q_{t}^{N}$ is computed using the point estimates of row (a) in Table 8 . 
Table 19

Variance Decomposition: The Vacancy Rate, Standard Model

\begin{tabular}{|l|c|c|}
\hline & variance value & relative to $\operatorname{var}\left(\ln \frac{v_{t}}{n_{t}}\right)$ \\
\hline $\operatorname{var}\left(\ln \frac{v_{t}}{n_{t}}\right)$ & 0.03 & 1 \\
\hline$\left(\frac{1}{\sigma-1}\right)^{2} \operatorname{var}\left[\ln \frac{e_{2}}{\mu_{t}}\right]$ & 0.05 & 1.8 \\
\hline$v\left(\frac{1}{\sigma-1}\right)^{2} \operatorname{var}\left[\ln \left(\frac{u_{t}}{n_{t}}\right)^{1-\sigma}\right]$ & 0.05 & 2.9 \\
\hline$\left(\frac{1}{\sigma-1}\right)^{2} \operatorname{var}\left[\ln \frac{Q_{t}^{N}}{\frac{f_{t}}{n_{t}}\left(1-\tau_{t}\right)}\right]$ & 0.09 & 1.3 \\
\hline$\left(\frac{1}{\sigma-1}\right)^{2} \operatorname{cov}\left[\ln \frac{\frac{e}{2}_{\mu_{t}}}{\mu^{\prime}} \ln \left(\frac{u_{t}}{n_{t}}\right)\right]$ & 0.04 & 0.3 \\
\hline$\left(\frac{1}{\sigma-1}\right)^{2} \operatorname{cov}\left[\ln \frac{e_{2}}{\mu_{t}}, \ln \frac{Q_{t}^{N}}{\frac{f_{t}}{n_{t}}\left(1-\tau_{t}\right)}\right]$ & 0.01 & -1.0 \\
\hline$\left(\frac{1}{\sigma-1}\right)^{2} \operatorname{cov}\left[\ln \left(\frac{u_{t}}{n_{t}}\right)^{1-\sigma}, \ln \frac{Q_{t}^{N}}{\frac{f_{t}}{n_{t}}\left(1-\tau_{t}\right)}\right]$ & -0.03 & 0.9 \\
\hline
\end{tabular}

Table 20

\section{Co-Movement: The Vacancy Rate, Standard Model}

\begin{tabular}{|l|l|}
\hline$\rho\left(\ln \frac{v_{t}}{n_{t}}, \ln f_{t}\right)$ & 0.89 \\
\hline$\rho\left(\ln \frac{e_{2}}{\mu_{t}}, \ln f_{t}\right)$ & 0.01 \\
\hline$\rho\left(\ln \left(\frac{u_{t}}{n_{t}}\right)^{1-\sigma}, \ln f_{t}\right)$ & -0.87 \\
\hline$\rho\left(\ln \frac{Q_{t}^{N}}{\frac{f_{t}}{n_{t}}\left(1-\tau_{t}\right)}, \ln f_{t}\right)$ & 0.90 \\
\hline$\rho\left(\ln \frac{v_{t}}{n_{t}}, \ln \frac{Q_{t}^{N}}{\frac{f_{t}}{n_{t}}\left(1-\tau_{t}\right)}\right)$ & 0.96 \\
\hline$\rho\left(\ln \frac{e_{2}}{\mu_{t}}, \ln \frac{Q_{t}^{N}}{\frac{f_{t}}{n_{t}}\left(1-\tau_{t}\right)}\right)$ & 0.27 \\
\hline$\rho\left(\ln \left(\frac{u_{t}}{n_{t}}\right)^{1-\sigma}, \frac{Q_{t}^{N}}{\frac{f_{t}}{n_{t}}\left(1-\tau_{t}\right)}\right)$ & -0.85 \\
\hline
\end{tabular}

Notes:

1. All series are logged and HP-filtered.

2. $Q_{t}^{N}$ is computed using the point estimates of row (d) in Table 8. 
Table 21

The Labor Share and GDP

$$
\rho\left(f_{t}, \frac{w_{t+i}}{\frac{f_{t+i}}{n_{t+i}}}\right)
$$

logged, HP filtered $(\lambda=1600)$

\begin{tabular}{cccccccc}
$i$ & -8 & -4 & -1 & 0 & 1 & 4 & 8 \\
\hline \hline & -0.36 & -0.38 & -0.29 & -0.23 & -0.02 & $\mathbf{0 . 5 3}$ & $\mathbf{0 . 4 6}$
\end{tabular}



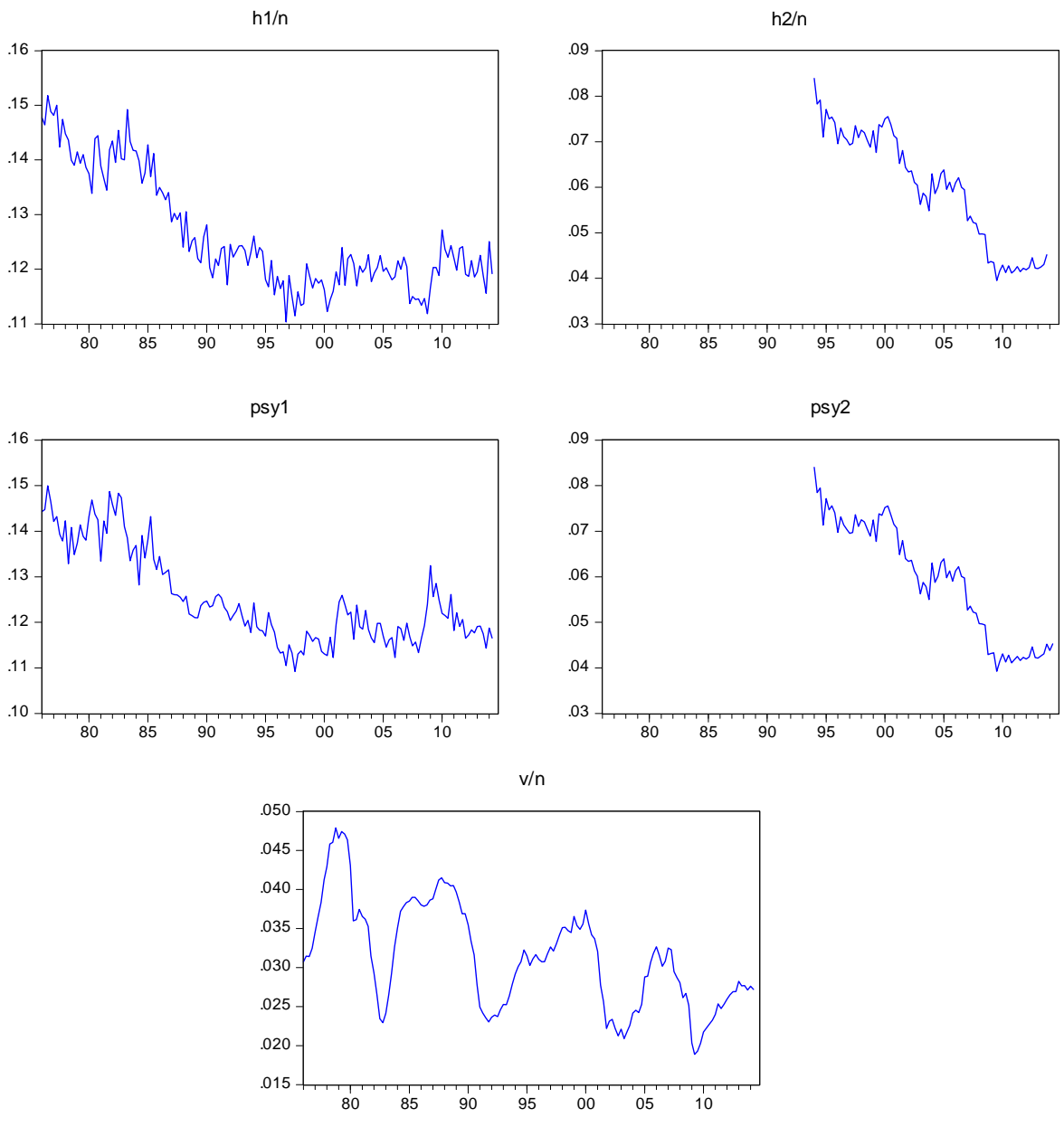

Figure 10: Decline in Worker Flows and Vacancy Rates 
Table 22

Decline in Labor Market Fluidity

$$
\frac{Q_{t}^{N}}{\frac{f_{t}}{n_{t}}}=(1-\tau) \frac{g_{v}}{q^{1} \frac{f}{n}}=\left(1-\tau_{t}\right) e_{3} \frac{i_{t}}{k_{t}}+\frac{\left(1-\tau_{t}\right)}{q_{t}^{1}} e_{2}\left(1-\lambda_{1}+\lambda_{1} q_{t}^{1}\right)^{2} \frac{v_{t}}{n_{t}}
$$

Data Averages

\begin{tabular}{|c|c|c|}
\hline & 1976:1-1995:4 & 1996:1-2013:4 \\
\hline$\frac{v_{t}}{n_{t}}$ & 0.035 & 0.028 \\
\hline$\tau_{t}$ & 0.41 & 0.34 \\
\hline$q_{t}^{1}$ & 4.0 & 4.4 \\
\hline$\frac{i_{t}}{k_{t}}$ & 0.022 & 0.026 \\
\hline
\end{tabular}

Parameter Point Estimates

\begin{tabular}{|l|l|}
\hline$e_{2}$ & 2.3 \\
\hline$e_{3}$ & -1.5 \\
\hline$\lambda_{1}$ & 0.9 \\
\hline
\end{tabular}

Job Value Estimates

\begin{tabular}{|c|c|c|}
\hline & 1976:1-1995:4 & 1996:1-2013:4 \\
\hline$\frac{Q_{t}^{N}}{\frac{f_{t}}{n_{t}}}$ & 0.135 & 0.126 \\
\hline
\end{tabular}




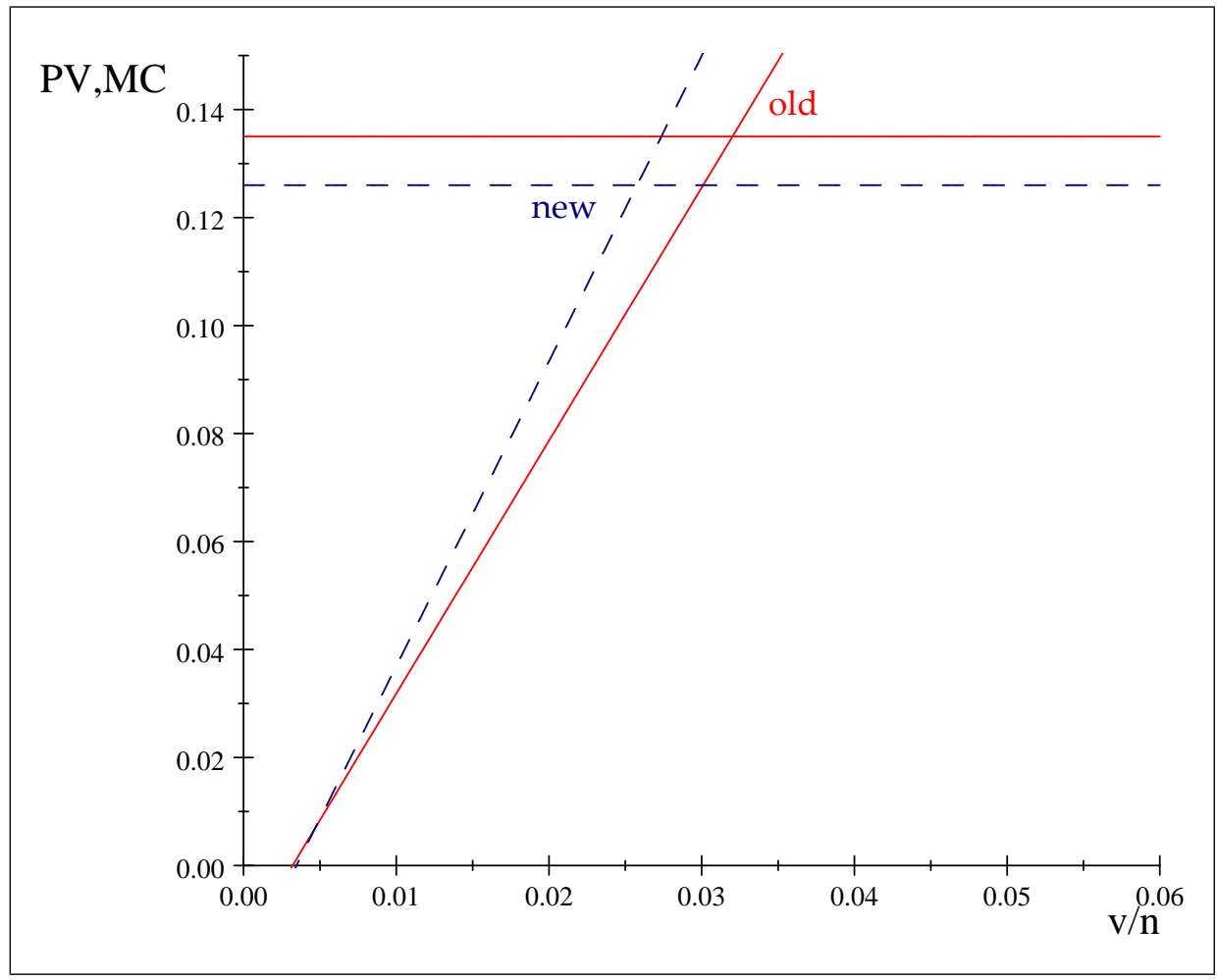

Figure 11: Job Values and Marginal Costs Across Sub-Periods 


\section{Appendix A: Alternative Formulations of The Va- cancy Creation/Hiring Equation (1)}

\section{Linear Costs Models}

\begin{tabular}{|c|c|c|c|}
\hline & paper & the hiring equation & reference \\
\hline 1 & Pissarides (2000, chapter 1$)$ & $\frac{(r+\lambda+\beta \theta q(\theta)) p c}{\beta(\theta)}=(1-\beta)(p-z)$ & eq $1.24, p .19$ \\
\hline 2 & Pissarides (2000, chapter 2$)$ & $\frac{c}{q(\theta)}=(1-\beta) \frac{1-R}{r+\lambda}$ & eq 2.14, p.43 \\
\hline \multirow[t]{2}{*}{3} & Shimer (2005) & $c\left[(r+s+\lambda) \frac{1}{q\left(\theta_{p, s}\right)}+\beta \theta_{p, s}\right]$ & eq $6, p .35$ \\
\hline & & $=(1-\beta)(p-z)+\lambda c E_{p, s} \frac{1}{q\left(\theta_{p^{\prime}, s^{\prime}}\right)}$ & \\
\hline \multirow[t]{2}{*}{4} & Hall (2005) & $k=\beta \rho\left(x_{s}\right) \sum_{s^{\prime}} \pi_{s s^{\prime}}\left(J_{s^{\prime}}-w_{s^{\prime}}\right) ; J_{s}$ & eqs. 4 and 5, p.54 \\
\hline & & $=z_{s}+\beta(1-\delta) \sum_{s^{\prime}} \pi_{s s^{\prime}}\left(J_{s^{\prime}}-w_{s^{\prime}}\right)$ & \\
\hline 5 & Hall and Milgrom (2008) & $c=q\left(\theta_{i}\right)\left(P_{i}-W_{i}\right)$ & eq.4, p.1657 \\
\hline 6 & Mortensen and Nagypal (2007) & $\frac{c \theta_{p}}{f\left(\theta_{p}\right)}=J_{p}=\frac{p-w_{p}-S J_{p}+\lambda\left(E_{p} J_{p \prime}-J_{p}\right)}{r}$ & eqs. 3 and 6 , pp.330-1 \\
\hline 7 & Hagedorn and Manovskii (2008) & $c_{p}=\delta q\left(\theta_{p}\right) E_{p} J_{p^{\prime}}$ & p. 1694 \\
\hline \multirow[t]{2}{*}{8} & Christiano et al (2013) & $\kappa \frac{1}{Q_{t}}=J_{t}=v_{t}^{p}-w_{t}^{p}$ & eqs. $7-10$, \\
\hline & & $=v_{t}-w_{t}+\rho \beta E_{t} \frac{C_{t}}{C_{t+1}}\left(v_{t+1}^{p}-w_{t+1}^{p}\right)$ & Appendix A1 \\
\hline 9 & Hall (2014a) & $\frac{c x}{H / V}=\frac{1}{1+r}\left(\frac{x-w}{r+s}\right)$ & eq 6, p. 5 ; eq. 11, p. 12 \\
\hline
\end{tabular}

\section{Convex Costs Models}

\begin{tabular}{|c|c|c|c|}
\hline & paper & the hiring equation & reference \\
\hline 1 & $\begin{array}{l}\text { Merz } \\
\& \text { Yashiv (2007) }\end{array}$ & $\begin{array}{l}\left(1-\tau_{t}\right) g_{h_{t}} \\
=E_{t}\left[m_{t+1}\left(1-\tau_{t+1}\right)\right. \\
\left.\left(f_{n_{t+1}}-g_{n_{t+1}}-w_{t+1}+\left(1-\psi_{t+1}\right) g_{h_{t+1}}\right)\right]\end{array}$ & eq F2, p.1421 \\
\hline 2 & $\begin{array}{l}\text { Gertler } \\
\& \text { Trigari (2009) }\end{array}$ & 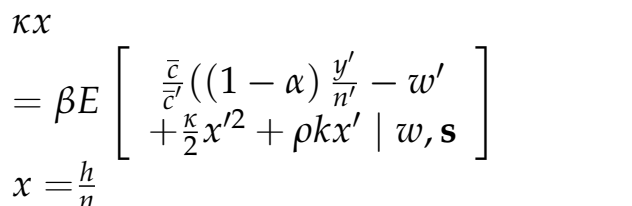 & eq.12, p. 45 \\
\hline 3 & Gali (2010) & $\left(\frac{P_{t}^{I}}{P_{t}}\right)(1-\alpha) A_{t} N_{t}(j)^{-\alpha}$ & eq 11, p.500 \\
\hline & & $=\left[\begin{array}{c}\frac{W_{t}(j)}{P_{t}} \\
+\Gamma\left(\frac{H_{t}}{U_{t}^{0}}\right)^{\frac{1-\tau}{\xi}} \\
-(1-\delta) E_{t}\left\{\beta \frac{C_{t}}{C_{t+1}} G_{t+1}\right\}\end{array}\right.$ & \\
\hline 4 & $\begin{array}{l}\text { Acemoglu } \\
\text { \& Hawkins (2014) }\end{array}$ & $\begin{array}{l}c^{\prime}(v)=q J_{n}(n . t ; z) ; J_{n}(n . t ; z) \\
=\frac{\phi}{1-\phi}\left[V(n, t ; z)-V^{u}(t)\right]\end{array}$ & eqs. 2 and 6, p. 588,590 \\
\hline
\end{tabular}




\section{Appendix B: The Estimating Equations}

\subsection{The Cost Function and its Derivatives}

$$
\begin{aligned}
& g(\cdot)=\left[\begin{array}{c}
\frac{e_{1}}{\eta_{1}}\left(\frac{i_{t}}{k_{t}}\right) \eta_{1} \\
+\frac{e_{2}}{\eta_{2}}\left[\frac{\left(1-\lambda_{1}-\lambda_{2}\right) v_{t}+\lambda_{1} q_{t}^{1} v_{t}+\lambda_{2} q_{t}^{2} v_{t}}{n_{t}}\right]^{\eta_{2}} \\
+\frac{e_{31}}{\eta_{31}}\left(\frac{i_{t}}{k_{t}} \frac{q_{t}^{1} v_{t}}{n_{t}}\right)^{\eta_{31}}+\frac{e_{32}}{\eta_{32}}\left(\frac{i_{t}}{k_{t}} \frac{q_{t}^{2} v_{t}}{n_{t}}\right)^{\eta_{32}}
\end{array}\right] f\left(z_{t}, n_{t}, k_{t}\right) \\
& \frac{g_{i_{t}}}{\frac{f_{t}}{k_{t}}}=\left[\begin{array}{c}
e_{1}\left(\frac{i_{t}}{k_{t}}\right)^{\eta_{1}-1} \\
+e_{31}\left(\frac{q_{t}^{1} v_{t}}{n_{t}}\right)^{\eta_{31}}\left(\frac{i_{t}}{k_{t}}\right)^{\eta_{31}-1}+e_{32}\left(\frac{q_{t}^{2} v_{t}}{n_{t}}\right)^{\eta_{32}}\left(\frac{i_{t}}{k_{t}}\right)^{\eta_{32}-1}
\end{array}\right] \\
& \frac{g_{v_{t}}}{\frac{f_{t}}{n_{t}}}=\left[\begin{array}{c}
e_{2}\left[\frac{\left(1-\lambda_{1}-\lambda_{2}\right) v_{t}+\lambda_{1} q_{t}^{1} v_{t}+\lambda_{2} q_{t}^{2} v_{t}}{n_{t}}\right]^{\eta_{2}-1}\left[\left(1-\lambda_{1}-\lambda_{2}\right)+\lambda_{1} q_{t}^{1}+\lambda_{2} q_{t}^{2}\right] \\
+e_{31} q_{t}^{1}\left(\frac{i_{t}}{k_{t}}\right)^{\eta_{31}}\left(\frac{q_{t}^{1} v_{t}}{n_{t}}\right)^{\eta_{31}-1} \\
+e_{32} q_{t}^{2}\left(\frac{i_{t}}{k_{t}}\right)^{\eta_{32}}\left(\frac{q_{t}^{2} v_{t}}{n_{t}}\right)^{\eta_{32}-1}
\end{array}\right] \\
& \frac{g_{k_{t}}}{\frac{f_{t}}{k_{t}}}=-\left[e_{1}\left(\frac{i_{t}}{k_{t}}\right)^{\eta_{1}}+e_{31}\left(\frac{q_{t}^{1} v_{t}}{n_{t}} \frac{i_{t}}{k_{t}}\right)^{\eta_{31}}+e_{32}\left(\frac{q_{t}^{2} v_{t}}{n_{t}} \frac{i_{t}}{k_{t}}\right)^{\eta_{32}}\right] \\
& +(1-\alpha)\left[\begin{array}{c}
\frac{e_{1}}{\eta_{1}}\left(\frac{i_{t}}{k_{t}}\right) \eta_{1} \\
+\frac{e_{2}}{\eta_{2}}\left[\frac{\left(1-\lambda_{1}-\lambda_{2}\right) v_{t}+\lambda_{1} q_{t}^{1} v_{t}+\lambda_{2} q_{t}^{2} v_{t}}{n_{t}}\right]^{\eta_{2}} \\
+\frac{e_{31}}{\eta_{31}}\left(\frac{i_{t}}{k_{t}} \frac{q_{t}^{1} v_{t}}{n_{t}}\right)^{\eta_{31}}+\frac{e_{32}}{\eta_{32}}\left(\frac{i_{t}}{k_{t}} \frac{q 2 v_{t}}{n_{t}}\right)^{\eta_{32}}
\end{array}\right] \\
& \frac{g_{n_{t}}}{\frac{f_{t}}{n_{t}}}=-\left[\begin{array}{c}
e_{2}\left[\frac{\left(1-\lambda_{1}-\lambda_{2}\right) v_{t}+\lambda_{1} q_{t}^{1} v_{t}+\lambda_{2} q_{t}^{2} v_{t}}{n_{t}}\right]^{\eta_{2}} \\
+e_{31}\left(\frac{q_{t}^{1} v_{t}}{n_{t}} \frac{i_{t}}{k_{t}}\right)^{\eta_{31}}+e_{32}\left(\frac{q_{t}^{2} v_{t}}{n_{t}} \frac{i_{t}}{k_{t}}\right)^{\eta_{32}}
\end{array}\right] \\
& +\alpha\left[\begin{array}{c}
\frac{e_{1}}{\eta_{1}}\left(\frac{i_{t}}{k_{t}}\right) \eta_{1} \\
+\frac{e_{2}}{\eta_{2}}\left[\frac{\left(1-\lambda_{1}-\lambda_{2}\right) v_{t}+\lambda_{1} q_{t}^{1} v_{t}+\lambda_{2} q_{t}^{2} v_{t}}{n_{t}}\right]^{\eta_{2}} \\
+\frac{e_{31}}{\eta_{31}}\left(\frac{i_{t}}{k_{t}} \frac{q_{t}^{1} v_{t}}{n_{t}}\right)^{\eta_{31}}+\frac{e_{32}}{\eta_{32}}\left(\frac{i_{t}}{k_{t}} \frac{q_{t}^{2} v_{t}}{n_{t}}\right)^{\eta_{32}}
\end{array}\right]
\end{aligned}
$$

\subsection{The Estimating Equations}

Replacing expected variables by actual ones and a rational expectations forecast error, the estimating equations are: 


$$
\left(1-\tau_{t}\right)\left(g_{i_{t}}+p_{t}^{I}\right)=\rho_{t, t+1}\left(1-\tau_{t+1}\right)\left[\begin{array}{c}
f_{k_{t+1}}-g_{k_{t+1}} \\
+\left(1-\delta_{t+1}\right)\left(g_{i_{t+1}}+p_{t+1}^{I}\right)
\end{array}\right]+j_{t}^{k}
$$

I estimate this equation after dividing throughout by $\frac{f_{t}}{k_{t}}$.

$$
\left(1-\tau_{t}\right) \frac{g_{v_{t}}}{q_{t}}=\rho_{t, t+1}\left(1-\tau_{t+1}\right)\left[\begin{array}{c}
f_{n_{t+1}}-g_{n_{t+1}}-w_{t+1} \\
+\left(1-\psi_{t+1}\right) \frac{g_{v_{t+1}}}{q_{t+1}}
\end{array}\right]+j_{t}^{n}
$$

I estimate this equation after dividing throughout by $\frac{f_{t}}{n_{t}}$.

As explained in the text, estimation pertains to $\alpha, e_{1}, e_{2}, e_{31}, e_{32}, \eta_{1}, \eta_{2}, \eta_{31}, \eta_{32}, \lambda_{1}, \lambda_{2}$ or a sub-set of these parameters.

\subsubsection{Tobin's Q Approach}

This approach ignores the other factor of production (i.e., assumes no adjustment costs for it), in the current case investment in capital. Hence in this case $e_{1}=e_{31}=e_{32}=0$ and $\eta_{2}=2$ and only equation (48) is estimated.

\subsubsection{The Standard Search and Matching Model}

In this case $e_{1}=e_{31}=e_{32}=0, \eta_{2}=1, \lambda_{1}=\lambda_{2}=0$ and there is only the hiring equation given by:

$$
\left(1-\tau_{t}\right) \frac{e_{2}}{q_{t}}=\left[\rho_{t, t+1}\left(1-\tau_{t+1}\right) \frac{\frac{f_{t+1}}{n_{t+1}}}{\frac{f_{t}}{n_{t}}}\left[\alpha-\frac{w_{t+1}}{\frac{f_{t+1}}{n_{t+1}}}+\left(1-\psi_{t+1}\right) \frac{e_{2}}{q_{t+1}}\right]\right]+j_{t}
$$

This is estimated for $e_{2}$ and $\alpha$. 


\section{Appendix C: the Data}

\begin{tabular}{l|l|l} 
variable & symbol & definition \\
\hline \hline GDP & $f$ & gross value added of NFCB \\
GDP deflator & $p^{f}$ & price per unit of gross value added of NFCB \\
wage share & $\frac{w n}{f}$ & numerator: compensation of employees in NFCB \\
discount rate & $r$ & the rate of non-durable consumption growth minus 1 \\
employment & $n$ & employment in nonfinancial corporate business sector \\
hiring & $h$ & gross hires \\
separation rate & $\psi$ & gross separations divided by employment \\
vacancies & $v$ & adjusted Help Wanted Index \\
investment & $i$ & gross investment in NFCB sector \\
capital stock & $k$ & stock of private nonresidential fixed assets in NFCB sector \\
depreciation & $\delta$ & depreciation of the capital stock \\
price of capital goods & $p^{I}$ & real price of new capital goods
\end{tabular}

\begin{tabular}{l|l|l} 
variable & symbol & source \\
\hline \hline GDP & $f$ & NIPA accounts, table 1.14, line 41 \\
GDP deflator & $p^{f}$ & NIPA table 1.15, line 1 \\
wage share & $\frac{w n}{f}$ & NIPA; see note 7 \\
discount rate & $r$ & NIPA Table 2.3.3, lines 3, 8, and 13; see \\
employment & $n$ & CPS; see note 2 \\
hiring & $h$ & CPS; see note 3 \\
separation rate & $\psi$ & CPS; see note 3 \\
vacancies & $v$ & Conference Board; see note 4 \\
investment & $i$ & BEA and Fed Flow of Funds; see note 5 \\
capital stock & $k$ & BEA and Fed Flow of Funds; see note 5 \\
depreciation & $\delta$ & BEA and Fed Flow of Funds; see note 5 \\
price of capital goods & $p^{I}$ & NIPA and U.S. tax foundation; see note 6
\end{tabular}

The sample period is 1976:2-2013:4 unless noted otherwise; all data are quarterly.

\section{Notes:}

1. The discount rate and the discount factor

The discount rate is based on a DSGE-type model with logarithmic utility $U\left(c_{t}\right)=\ln c_{t}$. Define the discount factor as $\rho_{t} \equiv \frac{1}{1+r_{t}}$

In this model:

$$
U^{\prime}\left(c_{t}\right)=U^{\prime}\left(c_{t+1}\right) \cdot\left(1+r_{t}\right)
$$

Hence:

$$
\rho_{t}=\frac{c_{t}}{c_{t+1}}
$$


where $c$ is non-durable consumption (goods and services) and $5 \%$ of durable consumption.

2. Employment

As a measure of employment in the nonfinancial corporate business sector $(n)$ I take wage and salary workers in non-agricultural industries (series ID LNS12032187) less government workers (series ID LNS12032188), less self-employed workers (series ID LNS12032192). All series originate from CPS databases. I do not subtract workers in private households (the unadjusted series ID LNU02032190) from the above due to lack of sufficient data on this variable.

3. Hiring and Separation Rates

The aggregate flow from non-employment - unemployment $(U)$ and out of the labor force $(O)$ - to employment is to be denoted $O E+U E$ and the separation rate $\psi_{t}$ is rate of the flow in the opposite direction, $E U+E O$. Worker flows within employment - i.e., job to job flows - are to be denoted EE.

I denote:

$$
\begin{aligned}
\frac{h}{n} & =\left(\frac{h^{1}}{n}\right)+\left(\frac{h^{2}}{n}\right) \\
\frac{h^{1}}{n} & =\frac{O E+U E}{E} \\
\frac{h^{2}}{n} & =\frac{E E}{E}
\end{aligned}
$$

Hence $h^{1}$ and $h^{2}$ denote flows from non-employment and from other employment, respectively.

Separation rates are given by:

$$
\begin{aligned}
\psi & =\psi^{1}+\psi^{2} \\
\psi^{1} & =\frac{E O+E U}{E} \\
\psi^{2} & =\frac{E E}{E}=\frac{h^{2}}{n}
\end{aligned}
$$

Employment dynamics now satisfies:

$$
\begin{aligned}
n_{t+1} & =\left(1-\psi_{t}^{1}-\psi_{t}^{2}\right) n_{t}+h_{t}^{1}+h_{t}^{2} \\
& =\left(1-\psi_{t}\right) n_{t}+h_{t}, \quad 0 \leq \psi_{t} \leq 1 \\
h_{t}^{2} & =\psi_{t}^{2}
\end{aligned}
$$

To calculate hiring and separation rates for the whole economy I use the following: 
a. The $h_{t}^{1}$ and $\psi_{t}^{1}$ flows. I compute the flows between $\mathrm{E}$ (employment), $\mathrm{U}$ (unemployment) and $\mathrm{O}$ (not-in-the-labor-force) that correspond to the $\mathrm{E}, \mathrm{U}, \mathrm{O}$ stocks published by the CPS. The methodology of adjusting flows to stocks is taken from BLS, and is presented in Frazis et al (2005). ${ }^{9}$ The data till 1990:Q1 were kindly provided by Ofer Cornfeld. The data from 1990:Q2 onwards were taken from the CPS (http:/ / www.bls.gov/cps/cps_flows.htm). Employment is the quarterly average of the original seasonally adjusted total employment series from BLS (LNS12000000).

b. The $h_{t}^{2}$ and $\psi_{t}^{2}$ flows. The data on EE, available only from 1994:Q1 onward, were computed by multiplying the percentage of people moving from one employer to another using Fallick and Fleischman $(2004){ }^{\prime} \mathrm{s}^{10}$ data by the NSA population series LNU00000000, taken from the CPS, completing several missing observations and performing seasonal adjustment.

4. Vacancies

I use the vacancies series based on the Conference Board Composite Help-Wanted Index that takes into account both printed and web job advertisements, as computed by Barnichon. The updated series is available at

https://sites.google.com/site/regisbarnichon/research/publications.

This index was multiplied by a constant to adjust its mean to the mean of the JOLTS vacancies series over the overlapping sample period (2001:Q12013:Q4)

5. Investment, capital and depreciation

The goal here is to construct the quarterly series for real investment flow $i_{t}$, real capital stock $k_{t}$, and depreciation rates $\delta_{t}$. I proceed as follows:

- Construct end-of-year fixed-cost net stock of private nonresidential fixed assets in NFCB sector, $K_{t}$. In order to do this I use the quantity index for net stock of fixed assets in NFCB (FAA table 4.2, line 37, BEA) as well as the 2009 current-cost net stock of fixed assets (FAA table 4.1, line 37, BEA).

- Construct annual fixed-cost depreciation of private nonresidential fixed assets in NFCB sector, $D_{t}$. The chain-type quantity index for depreciation originates from FAA table 4.5, line 37. The current-cost depreciation estimates (and specifically the 2009 estimate) are given in FAA table 4.4 , line 37.

- Calculate the annual fixed-cost investment flow, $I_{t}$ :

\footnotetext{
${ }^{9}$ Frazis, Harley J., Edwin L. Robison, Thomas D. Evans and Martha A. Duff, 2005. Estimating Gross Flows Consistent with Stocks in the CPS, Monthly Labor Review, September, 3-9.

${ }^{10}$ Fallick and Fleischman, 2004. “Employer-to-Employer Flows in the U.S. Labor Market: The Complete Picture of Gross Worker Flows," FEDS \#2004-34.
} 


$$
I_{t}=K_{t}-K_{t-1}+D_{t}
$$

- Calculate implied annual depreciation rate, $\delta_{a}$ :

$$
\delta_{a}=\frac{I_{t}-\left(K_{t}-K_{t-1}\right)}{K_{t-1}+I_{t} / 2}
$$

- Calculate implied quarterly depreciation rate for each year, $\delta_{q t}$ :

$$
\delta_{q}+\left(1-\delta_{q}\right) \delta_{q}+\left(1-\delta_{q}\right)^{2} \delta_{q}+\left(1-\delta_{q}\right)^{3} \delta_{q}=\delta_{a}
$$

- Take historic-cost quarterly investment in private non-residential fixed assets by NFCB sector from the Flow of Funds accounts, atabs files, series FA105013005).

- Deflate it using the investment price index (the latter is calculated as consumption of fixed capital in domestic NFCB in current dollars (NIPA table 1.14, line 18) divided by consumption of fixed capital in domestic NFCB in chained 2009 dollars (NIPA table 1.14, line 42). This procedure yields the implicit price deflator for depreciation in NFCB. The resulting quarterly series, $i_{t \_} u n a d j$, is thus in real terms.

- Perform Denton's procedure to adjust the quarterly series $i_{t \_} u n a d j$ from the Federal Flow of Funds accounts to the implied annual series from BEA $I_{t}$, using the depreciation rate $\delta_{q t}$ from above. I use the simplest version of the adjustment procedure, when the discrepancies between the two series are equally spread over the quarters of each year. As a result of adjustment I get the fixed-cost quarterly series $i_{t}$.

- Simulate the quarterly real capital stock series $k_{t}$ starting from $k_{0}\left(k_{0}\right.$ is actually the fixed-cost net stock of fixed assets in the end of 1975, this value is taken from the series $K_{t}$ ), using the quarterly depreciation series $\delta_{q t}$ and investment series $i_{t}$ from above:

$$
k_{t+1}=k_{t} \cdot\left(1-\delta_{q t}\right)+i_{t}
$$

6. Real price of new capital goods

In order to compute the real price of new capital goods, $p^{I}$, I use the price indices for output and for investment goods.

Investment in NFCB Inv consists of equipment $E q$ and structures $S t$ as well as intellectual property, which I do not include. I define the time-t price-indices for good $j=E q, S t$ as $\widetilde{p}_{t}^{j}$. The data are taken from NIPA table 1.1.4, lines 10, 11 . 
I take from http:/ / www.federalreserve.gov/econresdata/frbus/us-modelspackage.htm the following tax -related rates:

a. The parameter $\tau$ - the statutory corporate income tax rate as reported by the U.S. Tax Foundation.

b. The investment tax credit on equipment and public utility structures, to be denoted ITC.

c. The percentage of the cost of equipment that cannot be depreciated if the firm takes the investment tax credit, denoted $\chi$.

$\mathrm{d}$. The present discounted value of capital depreciation allowances, denoted $Z P D E^{S t}$ and $Z P D E^{E q}$.

I then apply the following equations:

$$
\begin{aligned}
p^{E q}=\widetilde{p}^{E q}\left(1-\tau_{E q}\right) \\
p^{S t}=\widetilde{p}^{S t}\left(1-\tau_{S t}\right), \\
1-\tau^{S_{t}}=\frac{\left(1-\tau Z P D E^{S t}\right)}{1-\tau} \\
1-\tau^{E q}=\frac{1-I T C-\tau Z P D E^{E q}(1-\chi I T C)}{1-\tau}
\end{aligned}
$$

Subsequently I compute their change between $t-1$ and $t$ (denoted by $\left.\Delta p_{t}^{j}\right)$ :

$$
\frac{\Delta p_{t}^{I n v}}{p_{t-1}^{I n v}}=\omega_{t} \frac{\Delta p_{t}^{E q}}{p_{t-1}^{E q}}+\left(1-\omega_{t}\right) \frac{\Delta p_{t}^{S t}}{p_{t-1}^{S t}}
$$

where

$$
\omega_{t}=\frac{\begin{array}{l}
\text { (nominal expenditure share of } E q \text { in } I n v)_{t-1} \\
+(\text { nominal expenditure share of } E q \text { in } \operatorname{Inv})_{t}
\end{array}}{2} .
$$

The weights $\omega_{t}$ are calculated from the NIPA table 1.1.5, lines 9,11.

I divide the series by the price index for output, $p_{t}^{f}$, to obtain the real price of new capital goods, $p^{I}$.

As all of these prices are indices, in estimation I estimate a scaling parameter $e^{a}$.

7. Labor share

NIPA table 1.14, line 20 (compensation of employees in NFCB) divided by line 17 in the same table (gross value added in NFCB). 


\section{Appendix D: The Approximation}

Equation (16) with the RHS iterated forward can be expressed as:

$$
\left(1-\tau_{t}\right) \frac{g_{v_{t}}}{q_{t}}=E_{t} \sum_{j=1}^{\infty}\left[\left(\prod_{l=1}^{j} \rho_{t+l-1, t+l}\right)\left(\prod_{l=2}^{j}\left(1-\psi_{t+l-1}\right)\right)\left(1-\tau_{t+j}\right)\left[f_{n_{t+j}}-g_{n_{t+j}}-w_{t+j}\right]\right]
$$

So the RHS of the F.O.C., to be denoted $P V_{t}$, can be written as:

$$
P V_{t}=E_{t} \sum_{j=1}^{\infty}\left[\begin{array}{c}
\left(\prod_{l=1}^{j} \rho_{t+l-1, t+l} \frac{\frac{f_{t+l}}{n_{t+l}}}{\frac{f_{t+l-1}}{n_{t+l-1}}}\right)\left(\prod_{l=2}^{j}\left(1-\psi_{t+l-1}\right)\right)\left(1-\tau_{t+j}\right) \\
{\left[\alpha-\frac{g_{n_{t+j}}}{\frac{f_{t+j}}{n_{t+j}}}-\frac{w_{t+j}}{\frac{f_{t+j}}{n_{t+j}}}\right]}
\end{array}\right]
$$

Using a truncated value going to $T$ rather than $\infty$ and dropping the expectations operator one gets:

$$
P V_{t, T}=\sum_{j=1}^{T}\left[\begin{array}{c}
\left(\prod_{l=1}^{j} \rho_{t+l-1, t+l} \frac{\frac{f_{t+l}}{n_{t+l}}}{\frac{f_{t+l-1}}{n_{t+l}-1}}\right)\left(\prod_{l=2}^{j}\left(1-\psi_{t+l-1}\right)\right)\left(1-\tau_{t+j}\right) \\
{\left[\alpha-\frac{g_{n_{t+j}}}{\frac{f_{t+j}}{n_{t+j}}}-\frac{w_{t+j}}{\frac{f_{t+j}}{n_{t+j}}}\right]}
\end{array}\right]
$$




\section{Appendix E: The Variance Decomposition}

The following derivation follows Cochrane (1992), noting that the latter does a second order Taylor expansion while here a first -order one is undertaken. Define:

$$
\begin{aligned}
M P_{t+j} \equiv & \left.\left(1-\tau_{t+j}\right)\left(\alpha-\frac{g_{n_{t+j}}}{\frac{f_{t+j}}{n_{t+j}}}-\frac{w_{t+j}}{\frac{f_{t+j}}{n_{t+j}}}\right)\right) \\
g_{t}^{f} & =\ln \left(\frac{\frac{f_{t+1}}{\frac{n_{t+1}}{n_{t}}}}{n_{t}}\right) \\
g_{t}^{s} & \equiv \ln \left(1-\psi_{t}\right) \\
g_{t}^{r} & \equiv \ln \rho_{t, t+1} \equiv \ln \left(\frac{1}{1+r_{t}}\right) \\
w_{t} & \equiv\left(g_{t}^{f}+g_{t}^{s}+g_{t}^{r}\right)
\end{aligned}
$$

and

$$
\begin{aligned}
\Omega^{f} & =e^{E\left(g_{t}^{f}\right)} \\
\Omega^{s} & =e^{E\left(g_{t}^{s}\right)} \\
\Omega^{r} & =e^{E\left(g_{t}^{r}\right)} \\
\Omega & =e^{E(w)}=\Omega^{f} \Omega^{s} \Omega^{r}
\end{aligned}
$$

Then (55) implies the present value relationship:

$$
P_{t} \equiv\left(1-\tau_{t}\right) \frac{g_{v_{t}}}{q_{t}}=E_{t}\left[\sum_{j=1}^{\infty} \exp \left[\sum_{l=1}^{j} g_{t+l}^{r}\right] \exp \left[\sum_{l=1}^{j} g_{t+l}^{f}\right] \exp \left[\sum_{m=l}^{j} g_{t+m-1}^{s}\right] M P_{t+j}\right]
$$

Multiply both sides by any variable $Z_{t}$ observed at time $t$ and take expectations:

$$
E\left(Z_{t} P_{t}\right)=E\left[Z_{t} \sum_{j=1}^{\infty} \exp \left[\sum_{l=1}^{j} g_{t+l}^{r}\right] \exp \left[\sum_{l=1}^{j} g_{t+l}^{f}\right] \exp \left[\sum_{l=2}^{j} g_{t+l-1}^{s}\right] M P_{t+j}\right]
$$

The first order Taylor expansion of the term in square brackets is: 


$$
\begin{aligned}
& Z_{t} \sum_{j=1}^{\infty} \exp \left[\sum_{l=1}^{j} g_{t+l}^{r}\right] \exp \left[\sum_{l=1}^{j} g_{t+l}^{f}\right] \exp \left[\sum_{l=2}^{j} g_{t+m-1}^{s}\right] M P_{t+j} \\
\cong & Z_{t} \frac{\Omega^{r} \Omega^{f}}{1-\Omega} E(M P)+E(Z) \frac{\Omega^{r} \Omega^{f}}{1-\Omega} E(M P) \sum_{j=1}^{\infty}(\Omega)^{j-1} \widetilde{g}_{t+j}^{r}+E(Z) \frac{\Omega^{r} \Omega^{f}}{1-\Omega} E(M P) \sum_{j=1}^{\infty}(\Omega)^{j-1} \widetilde{g}_{t+j}^{f} \\
& +E(Z) \frac{\Omega^{r} \Omega^{f}}{1-\Omega} E(M P) \sum_{j=2}^{\infty}(\Omega)^{j-1} \widetilde{g}_{t+j}^{s}+E(Z) \Omega^{r} \Omega^{f} \sum_{j=1}^{\infty}(\Omega)^{j-1} \widetilde{M P}_{t+j}
\end{aligned}
$$

Multiplying by $P_{t}-E(P)$ and taking expectations yields the variance decomposition:

$$
\begin{aligned}
\operatorname{var}(P) \cong & \frac{\Omega^{r} \Omega^{f} E(M P)}{1-\Omega} \sum_{j=1}^{\infty}(\Omega)^{j-1} \operatorname{cov}\left(P_{t}, g_{t+j}^{r}\right)+ \\
& \frac{\Omega^{r} \Omega^{f} E(M P)}{1-\Omega} \sum_{j=1}^{\infty}(\Omega)^{j-1} \operatorname{cov}\left(P_{t}, g_{t+j}^{f}\right)+ \\
& \frac{\Omega^{r} \Omega^{f} E(M P)}{1-\Omega} \sum_{j=2}^{\infty}(\Omega)^{j-1} \operatorname{cov}\left(P_{t}, g_{t+j}^{s}\right)+ \\
& \Omega^{r} \Omega^{f} \sum_{j=1}^{\infty}(\Omega)^{j-1} \operatorname{cov}\left(P_{t}, M P_{t+j}\right)
\end{aligned}
$$

